\title{
Solanaceae endémicas del Perú
}

\author{
Sandra Knapp 1, David M. Spooner ${ }^{2}$ y Blanca León ${ }^{3,4}$
}

\begin{abstract}
${ }^{1}$ Department of Botany, The Natural History Museum, Cromwell Road, London SW7 5BD, Reino Unido. s.knapp@nhm.ac.uk

${ }^{2}$ University of Wisconsin, Horticulture Department, Potato Introduction Station, Sturgeon Bay, WI 54235, EE.UU.

dspooner@wisc.edu

${ }^{3}$ Museo de Historia Natural, Av. Arenales 1256, Aptdo. 14-0434, Lima 14, Perú.

${ }^{4}$ Plant Resources Center, University of Texas at Austin, Austin TX 78712 EE.UU.

blanca.leon@mail.utexas.edu
\end{abstract}

\begin{abstract}
Resumen
La familia Solanaceae es una de las más ricas en especies en la flora peruana, siendo reconocida con alrededor de 42 géneros y 600 especies (Brako \& Zarucchi, 1993; Ulloa Ulloa et al., 2004), principalmente hierbas y arbustos. En este trabajo reconocemos 208 especies y seis variedades como endémicos, en 16 géneros. Esta familia ocupa el sexto lugar por su diversidad en especies endémicas, siendo Solanum, Nolana y Jaltomata los géneros más ricos en especies. Los taxones endémicos se encuentran en la mayoría de las regiones, principalmente en Mesoandina, Desierto Semicálido Tropical y Bosques Muy Húmedos Montanos, desde el nivel del mar hasta los $3800 \mathrm{~m}$ de altitud. Treinta y seis taxones se encuentran representados dentro del Sistema Nacional de Áreas Naturales Protegidas por el Estado.
\end{abstract}

Palabras claves: Solanaceae, Solanum, Nolana, Jaltomata, Perú, endemismo, plantas endémicas.

\section{Abstract}

The Solanaceae are among the most diverse families in the Peruvian flora, with about 42 genera and 600 species (Brako \& Zarucchi, 1993; Ulloa Ulloa et al., 2004), mostly herbs and shrubs. Here we recognize as endemics 203 species and six varieties in 16 genera. This family ranks $6^{\text {th }}$ among the most diverse families in endemic taxa. Solanum, Nolana and Jaltomata are the genera with more endemic species. Endemic taxa are found in almost all regions, mainly Mesoandean, Very Humid Montane Forests and Subtropical Costal Desert, from sea level 100 to 3800 m elevation. Thirty-six taxa have been recorded within Peru's protected areas system.

Keywords: Solanaceae, Solanum, Nolana, Jaltomata, Peru, endemism, endemic plants.

\section{Browallia mirabilis S. Leiva NE}

Publicación: Arnaldoa 3(2): 13. 1995. Colección tipo: S. Leiva et al. 1591 Herbarios: CONN, CORD, F, MO, NY; HAO.

Nombre común: D esconocido.

Registro departamental: CA.

Regiones Ecológicas: BMHM; 1460$1650 \mathrm{~m}$.

SINAN PE: Sin registro.

Herbarios peruanos: $\mathrm{HAO}$ (holotipo), HUT (1), USM (1).

Observaciones: Esta especie es de estatus taxonómico incierto (A. Sagástegui, com. pers., 2004); probablemente se trate de Browallia americana o B. speciosa. Por ello no se la evalúa hasta resolver esta condición.

\section{Capsicum tovanii Eshbaugh, Smith \& Nickrent}

$$
\text { EN, Blab(iii) }
$$

Publicación: Brittonia 35(1): 55. 1983.

Colección tipo: O. Tovar 1867

Henbarios: MU, US; USM!

Nombre común: Mucuru uchu; ají silvestre.

Registro departamental: HV, JU.

Regiones Ecológicas: MA; 2000- 2200

m.

SINAN PE: Sin registro.

Herbarios peruanos: USM (holotipo+1).
Observaciones: Arbusto caducifolio, conocido solamente de dos localidades, en el valle del Mantaro. Al parecer, no hay colecciones desde 1979, probablemente por lo poco herborizado que es el valle y en general los ambientes interandinos. El valle del Mantaro es uno de los más densamente poblados; el uso de matorrales semixéricos está limitado al pastoreo de ganado ovino y caprino que podría afectar a las poblaciones de esta especie.

\section{Cestrum dunalii Francey}

\section{EN, Blab(iii)}

Publicación: Candollea 6: 353-354. 1935- 1936.

Colección tipo: A. Mathews 3251; A. Raimondi 923

Herbarios: BM, G, K.

Nombre común: D esconocido.

Registro departamental: AM, CA.

Regiones Ecológicas: MA; altitud desconocida.

SINAN PE: Sin registro.

Hemarios penuanos: HUT (1)?.

Observaciones: Arbusto conocido solamente del norte del país, de las cuencas del Marañón y del Utcubamba. La recolección más reciente, en 1976, proviene de Cajamarca. Los bosques y matorrales en Cajamarca están afectados por el avance de la frontera agrícola, lo que podría considerarse una amenaza para las poblaciones de esta especie.

Nota del Editor: En la versión on line de este artículo han sido omitidos los mapas del Perú que ilustraban el Registro departamental. Para ubicar las abreviaturas de los departamentos vea al final del artículo. 


\section{Cestrum falcatum Francey var. falcatum}

\section{NE}

Publicación:

Colección tipo: F. Herrera 734

Herbarios: P.

Nombre común: D esconocido.

Registro departamental: CU.

Regiones Ecológicas: MA; 2800- 2900 m.

SINANPE: Sin registro.

Herbarios peruanos: Ninguno.

Observaciones: Arbusto conocido sólo de una localidad no precisada, en el valle del Urubamba. Brako \& Zarucchi (1993) indicaron presencia en Lima, pero no hay ejemplares recolectados de esta especie en ese D epartamento. La descripción original señala la cercanía morfológica con Cestrum conglomeratum, pero no hay una revisión taxonómica moderna que evalúe si son coespecíficas, por ello se la deja sin evaluar.

\section{Cestrum falcatum Francey var. soukupii J.F. Macbr. \\ NE}

Publicación: Field Mus. Nat. Hist., Bot. Ser. 13(5B/ 1): 101. 1962.

Colección tipo: J. Soukup 3674

Herbarios: US.

Nombre común: D esconocido.

Registro departamental: JU.

Regiones Ecológicas: BMHM; altitud desconocida.

SINAN PE: Sin registro.

Hembarios peruanos: Ninguno.

Observaciones: Arbusto conocido sólo de una localidad, la cual se consideró se ubicaba en Lima, pero en realidad corresponde a Junín. Al igual que la variedad típica se la deja sin evaluar, pendiente de una revisión taxonómica del género.

\section{Cestrum glaucophyllum Francey}

\section{CR, B lab(iii)}

Publicación: Candollea 6: 149-151. 1935- 1936.

Colección tipo: E.P. Killip \& A.C. Smith 25740

Herbarios: F, NY, US.

Nombre común: D esconocido.

Registro departamental: PA.

Regiones Ecológicas: BMHM; 1600$1900 \mathrm{~m}$.

SINANPE: Sin registro.

Herbarios peruanos: Ninguno.

Observaciones: Esta especie arbórea se conoce solamente de una localidad. Brako \& Zarucchi (1993) indicaron su presencia en Junín, tal como seindica en la descripción original, pero la localidad original corresponde hoy a Pasco. La zona ha sido objeto de constante herborización, pero no hay ejemplares adicionales. Probablemente representada en el Parque Nacional Yanachaga-Chemillén 0 vecindades. El rango altitudinal de la especie ha sido poco botanizado y es al mismo tiempo una de las zonas proclives a deforestación fuera de las áreas protegidas.

\section{Cestrum laevifolium Francey}

CR, Blab(iii)

Publicación: Candollea 7: 62. 1936. Colección tipo: E.P. Killip \& A.C. Smith 26074

Hemarios: F, NY, US.

Nombre común: D esconocido.

Registro departamental: JU.

Regiones Ecológicas: BMHP; 1100 m.

SINAN PE: Sin registro.

Herbarios peruanos: Ninguno.

Observaciones: Especie arbórea conocida de una sola localidad, ubicada, probablemente, entre los D epartamentos de Junín y Pasco. La localidad original estaba ubicada a lo largo de un camino antiguo de arrieros, que incluía fragmentos de bosque modificado en 1929. Hoy las áreas premontanas de Junín y Pasco están sujetas a intensa deforestación por la expansión agrícola.

\section{Cestrum macbridei Francey}

\section{NE}

Publicación: Candollea 6: 262-263. 1935- 1936.

Colección tipo: J.F. Macbride 5724

Hemarios: F, US.

Nombre común: D esconocido.

Registro departamental: JU.

Regiones Ecológicas: BMHP; $1200 \mathrm{~m}$.

SINAN PE: Sin registro.

Herbarios peruanos: Ninguno.

Observaciones: Especie arbustiva, morfológicamente similar a Cestrum foliosum, del Perú y Bolivia. Se conoce solamente de una localidad ubicada en el valle del río Chanchamayo, el cual está fuertemente impactado por la actividad agrícola. D ebido a la falta de certeza en el estatus taxonómico de esta especie no se la evalúa.

\section{Cestrum obscurum Francey}

CR, Blab(iii)

Publicación: Candollea 6: 302-303. 1935- 1936.

Colección tipo: A. Weberbauer 1930

Herbarios: B.

Nombre común: D esconocido.

Registro departamental: JU.

Regiones Ecológicas: BMHP; $1000 \mathrm{~m}$.

SINANPE: Sin registro.

Herbarios peruanos: Ninguno.

Observaciones: Esta especie arbustiva fue descrita de un ejemplar recolectado en el valle del Chanchamayo, a inicios del siglo XX. No hay material de herbario adicional, si bien este valle ha sido objeto de constante herborización. Todo el valle del Chanchamayo, pero en especial la zona premontana, está muy deforestado.

\section{Cestrum ovalifolium Francey}

\section{NE}

Publicación: Candollea 6: 362-363. 1935.

Colección tipo: C. Jelski 6549

Herbarios:

Nombre común: D esconocido.

Registro departamental: CA.

Regiones Ecológicas: $\mathrm{BMHM}$; altitud desconocida.

SINANPE: PNC

Herbarios peruanos: Ninguno. 
Observaciones: Esta especie arbustiva fue reconocida como distinta de Cestrum dunalii por la forma foliar, pero probablemente sea coespecífica con esta. No se conoce de ejemplares adicionales y la localidad original se halla ubicada en el área que hoy ocupa un área protegida.

\section{Cestrum ovato-lanceolatum Francey}

\author{
NE \\ Publicación: Candollea 6: 279-280. \\ 1935- 1936. \\ Colección tipo: J.F. Macbride 5435 \\ Hemarios: $F$. \\ Nombre común: D esconocido. \\ Registro departamental: JU. \\ Regiones Ecológicas: BMHP; $600 \mathrm{~m}$. \\ SINAN PE: Sin registro. \\ Herbarios peruanos: Ninguno.
}

Observaciones: Esta especie arbórea fue descrita de un ejemplar recolectado en el valle del Chanchamayo, en 1923. No hay colecciones adicionales. Brako \& Zarucchi (1993) indicaron Loreto como parte de la distribución de esta especie, pero el único ejemplar de Loreto fue mencionado por Macbride, con dudas de su propia identificación, por ello se excluye.

\section{Cestrum pseudopedicellatum Francey}

$$
\text { CR, Blab(iii) }
$$

Publicación: Candollea 7: 29-30. 1936.

Colección tipo: A. Weberbauer 6675

Herbarios: G; MOL!.

Nombre común: D esconocido.

Registro departamental: JU.

Regiones Ecológicas: BMHM; 2700$2800 \mathrm{~m}$.

SINANPE: Sin registro.

Herbarios penuanos: MOL (isotipo).

Observaciones: Esta especie arbustiva se conoce sólo de una localidad, ubicada en el D epartamento de Junín. La colección original, fue citada por Weberbauer (1945) como parte de su descripción del valle del Masamerich. Sin embargo, fue incluida por Brako \& Zarucchi (1999) como de procedencia desconocida, tal como fue mencionada por Macbride (1962). La localidad original en la Provincia de Satipo ha sido poco herborizada desde 1913. Además está ubicada en una de las zonas con deforestación muy avanzada.

\section{Cestrum raimondianum Francey}

\section{EN, Bla}

Publicación: Candollea 6: 382-383. 1935- 1936.

Colección tipo: A. Raimondi 1055

Herbarios: B.

Nombre común: Yerba santa.

Registro departamental: AM, CA.

Regiones Ecológicas: MA; altitud desconocida.

SINAN PE: Sin registro.

Herbarios peruanos: USM?.

Observaciones: Especie arbustiva conocida sólo de la cuenca del Marañón y del Utcubamba. No ha vuelto a ser recolectada desde 1938. Al parecer, ocupa matorrales de la región Mesoandina; si bien, se sabe poco de su rango altitudinal, por su distribución limitada se la considera amenazada.

\section{Cestrum undulatum Ruiz \& Pav.}

LC

Publicación: Fl. Peruv. 2: 28, t. 155. 1799. Colección tipo: H. Ruiz \& J. Pavón s.n.

Herbarios: B.

Nombre común: Yerba hedionda, yerba santa. Registro departamental: AM, HU, JU, LI, LO.

Regiones Ecológicas: $\mathrm{BMHM}, \mathrm{BMHP}$, BHA; $100-1850 \mathrm{~m}$.

SINAN PE: Sin registro.

Hembarios peruanos: USM (1).

Observaciones: Esta especie arbustiva, probablemente sea coespecífica con Cestrum microcalyx, de distribución amplia en el Neotrópico. El rango altitudinal de esta especie es amplio y según Macbride (1962) se le halla como ornamental.

\section{Cestrum weberbauen Francey}

$$
\text { EN, Blab(iii) }
$$

Publicación: Candollea 7: 5-6. 1936.

Colección tipo: A. Weberbauer 4254

Herbarios: G; MOL!.

Nombre común: D esconocido.

Registro departamental: AM, CA.

Regiones Ecológicas: MA, BS; 2000$3040 \mathrm{~m}$.

SINAN PE: Sin registro.

Herbarios penuanos: HAO (2), HUT (1), MOL (isotipo).

Observaciones: Esta especie arbustiva se conoce de varias localidades, en la cuenca del Marañón. Habita matomales en laderas semixéricas. Amenazas potenciales podrían incluir el pastoreo intensivo.

\section{Dunalia spathulata (Ruiz \& Pav.) Braun \& Bouché}

\section{VU, Bla}

Publicación: Index Sem. (Berlin) App. 6. 1821. Colección tipo: H. Ruiz s.n.

Hemanios: B.

Nombre común: D esconocido.

Registro departamental: HU.

Regiones Ecológicas: MA; 1820 m.

SINAN PE: Sin registro.

Herbarios penuanos: HAO (2).

Observaciones: De acuerdo con Smith \& Leiva G onzalez (2006), esta especie arbustiva debe considerarse una endémica peruana, si bien no fue reconocida como tal por Brako \& Zarucchi (1993). Es conocida del centro oriente del país y las poblaciones, representadas en el material de herbario, provienen de matorrales asociados a campos de cultivo y otras zonas modificadas por la agricultura.

\section{Exodeconus prostratus (L'Her.) Raf.}

\section{LC}

Publicación: Sylva Tellur. 57. 1838.

Colección tipo: J. D ombey s.n.

Herbarios: $P$.

Nombre común: Campanilla cimarrona, campiña cimarrona.

Registro departamental: AN, CA, IC, LL, LI, PI.

Regiones Ecológicas: D ST, MDE; 150$1400 \mathrm{~m}$.

SINANPE: RNL 
Herbarios penuanos: CPUN (4), HAO (6), HUT (10), USM (11).

Observaciones: Esta especie herbácea se conocede numerosas poblaciones fragmentadas, a lo largo de la costa y piedemonte occidental. Se halla creciendo como maleza en las lomas costeras.

\section{Hawkesiophyton klugii (Damm.) H unz.}

\section{EN, Bla}

Publicación: Kurtziana 10: 40, 42, f. 11

H-O. 1977.

Colección tipo: G. Klug 126

Herbarios: US.

Nombre común: D esconocido.

Registro departamental: LO, UC.

Regiones Ecológicas: BHA; 100 m.

SINAN PE: Sin registro.

Herbarios peruanos: Ninguno.

Observaciones: Especie arbustiva escandente, conocida sólo de la Amazonía peruana, de dos poblaciones, separadas entre ellas por más de $600 \mathrm{~km}$ en línea recta. Knapp et al. (1997) encontraron evidencia para reconocer el género en M arkea; sin embargo, no hay combinación nomenclatural para esta especie endémica en ese género. Podría estar representada en el Parque Nacional Alto Purús.

\section{Iochroma albianthum S. Leiva}

\section{DD}

Publicación: Arnaldoa 12(1-2): 72-76, f. 1. [2005] 2006.

Colección tipo: S. Leiva et al. 2746

Herbarios: CCSU, CORD, F, M, MO, NY, WIS; HAO, HUSA, USM.

Nombre común: D esconocido.

Registro departamental: PI.

Regiones Ecológicas: MA; $2600 \mathrm{~m}$.

SINAN PE: Sin registro.

Hemarios penuanos: HAO (holotipo+2),

HUT (1), HUSA (isotipo+1), USM (isotipo+2).

Observaciones: Árbol conocido de dos colecciones realizadas en la cuenca del Quiroz. Esta especie está asociada a matorrales intervenidos en los alrededores de campos de cultivo. Se desconoce el estado actual de sus poblaciones.

\section{Iochroma ayabacense S. Leiva}

\section{DD}

Publicación: Arnaldoa 12(1-2): 76-80, f. 2. [2005] 2006.

Colección tipo: S. Leiva 2620

Henbarios: CCSU, CORD, F, MO; $\underline{\mathrm{HAO}}$.

Nombre común: D esconocido.

Registro departamental: PI

Regiones Ecológicas: MA; 2360- 2700 $\mathrm{m}$.

SINAN PE: Sin registro.

Herbarios penuanos: HAO (holotipo+8), HUSA (1), HUT (3), USM (1).

Observaciones: Arbusto localmente escaso, conocido de unas pocas localidades, en la cuenca del Quiroz. Según Leiva (2006), presenta afinidades con Iochroma stenanthum del suroeste de Cajamarca; la cual parece ser una de las especies parentales de este probable híbrido (Smith \& Baum, 2006).

\section{Iochroma edule S. Leiva}

\section{LC}

Publicación: Arnaldoa 3(1): 41-44. 1995. Colección tipo: S. Leiva 943

Herbarios: CONN, CORD, F, MO, NY; HAO!, HUT!, USM!.

Nombre común: Lusaque.

Registro departamental: CA, LL.

Regiones Ecológicas: MA, BS; 1900$3000 \mathrm{~m}$.

SINANPE: Sin registro.

Hemarios penuanos: $\mathrm{HAO}$ (holotipo+9), HUT (isotipo+2), USM (isotipo+5).

Observaciones: Arbusto conocido sólo de unas cuatro localidades, en el norte del país, en la vertiente occidental. Descrita como localmente frecuente, esta especie tiene frutos comestibles. Su rango de presencia alcanza aproximadamente $600 \mathrm{~km}^{2}$.

\section{Iochroma nitidum S. Leiva \& Q uipuscoa}

$$
\text { EN, B lab(i, iii) }
$$

Publicación: Amaldoa 5(2): 172, f. 1. 1998. Colección tipo: V. Quipuscoa et al. 932 Henbarios: CONN, CORD, F, MO; $\underline{\mathrm{HAO} \text { !. }}$ Nombre común: D esconocido. Registro departamental: AM, SM. Regiones Ecológicas: BMHM; 2500$3400 \mathrm{~m}$.

SINAN PE: Sin registro.

Herbarios peruanos: HAO (holotipo), HUT (1), USM (3).

Observaciones: Esta especie arbustiva se conoce de pocas localidades, en el noreste del país, en un área menor a los $5000 \mathrm{~km}^{2}$. Según Leiva \& Quipuscoa (1998), se emplea localmente para cercos y su madera para construcción y leña. Amenazas provienen de la deforestación.

\section{Iochroma salpoanum S. Leiva \& P. Lezama}

\section{NE}

Publicación: Amaldoa 10(1): 96, f. 1. 2003. Colección tipo: S. Leiva \& P. Leiva 542 Henbarios: CORD, F, MO ; $\mathrm{HAO}$ !. Nombre común: D esconocido. Registro departamental: LL. Regiones Ecológicas: MA; 2600-2710 m. SINANPE: Sin registro.

Herbarios penuanos: $\mathrm{HAO}$ (holotipo+7), USM (1).

Observaciones: Esta especie arbustiva, se conoce de una localidad del noroccidente del país. Probablemente sea coespecífica con Iochroma umbellatum. Leiva et al. (2003), señalan que es escasa en la única localidad de la que se la conoce. Por la incertidumbre taxonómica no se la evalúa.

\section{Iochroma schjellerupiae S. Leiva \& Quipuscoa DD}

Publicación: Arnaldoa 5(2): 175, 177, f. 2. Como «schjellerupii». 1998.

Colección tipo: S. Leiva et al. 1861

Herbarios: CONN, CORD, F, MO; $\mathrm{HAO}$ !, HUT!.

Nombre común: Saburrión grande.

Registro departamental: PI.

Regiones Ecológicas: MA; 2600-2660 m. SINANPE: Sin registro.

Herbarios peruanos: $\mathrm{HAO}$ (holotipo, isotipo), HUT (isotipo). 
Observaciones: Esta especie arbustiva se conoce sólo de una localidad, en la cuenca alta del río Q uiroz, muy cerca al límite internacional con Ecuador. Sus poblaciones ocupan ambientes impactados por la actividad humana, pero no hay referencias al tamaño de las poblaciones. La localidad original ha sido escasamente herborizada. Se desconoce el estado actual de sus poblaciones.

\section{Iochroma squamosum S. Leiva \& Q uipuscoa}

$$
\text { EN, Blab(iii) }
$$

Publicación: Arnaldoa 10(1): 99-100, 102, f. 2. 2003.

Colección tipo: S. Leiva et al. 2028

Herbarios: CCSU, CORD, F; $\underline{\mathrm{HAO}}$ !.

Nombre común: D esconocido.

Registro departamental: PI.

Regiones Ecológicas: MA; 2540-2730 m.

SINAN PE: Sin registro.

Herbarios penuanos: HAO (holotipo+2), USM (3).

Observaciones: Arbusto o árbol conocido de unas dos localidades, en áreas asociadas a los relictos de bosques de las vertientes occidentales. Leiva et al. (2003) señalan que es abundantelocalmente. Smith \& Baum (2006) indicaron que podría ser una de las especies parentales de Iochroma ayabacense. Amenazas a sus poblaciones proviene de la deforestación.

\section{Iochroma stenanthum S. Leiva, Quipuscoa \& Sawyer}

\section{NE}

Publicación: Amaldoa 5(1): 78- 81, f. 1. 1998.

Colección tipo: A. Sagástegui A. et al. 15458

Herbarios: CONN, CORD, F; $\underline{\mathrm{HAO} \text { !. }}$

Nombre común: D esconocido.

Registro departamental: CA.

Regiones Ecológicas: MA; 1976- 2578 m.

SINAN PE: Sin registro.

Herbarios peruanos: HAO (holotipo+6), HUT (2), USM (1).

Observaciones: Esta especie arbustiva ha sido descrita de plantas provenientes de las cercanías de campos de cultivo, en la vertiente occidental. Probablemente es parte de la variación de Iochroma cornifolium. No se la evalúa hasta aclarar su estatus taxonómico.

\section{Jaltomata andersonii Mione}

$$
\text { VU, Bla }
$$

Publicación: Rhodora 106(926): 119122, f. 1. 2004.

Colección tipo: T. Mione et al. 622

Herbarios: CONN, NY.

Nombre común: D esconocido.

Registro departamental: AN, LI.

Regiones Ecológicas: MA; 2300-3400 m.

SINAN PE: Sin registro.

Herbanios penuanos: HAO (2), HUT (2), MOL (1).

Observaciones: Especie herbácea, de frutos probablemente comestibles, conocida de la vertiente del Pacífico, ocupando las cuencas del Rímacy Nepeña, en zonas dondela agriculturay ganadería son las principales actividades. Aparentemente mantiene banco de semillas, pues Mione (2004) indica la presencia de plantas durante eventos de El Niño.
28. Jaltomata aspera (Ruiz \& Pav.) Mione \& F.G. Coe

$$
\text { EN, Blab(i, iii)+2a }
$$

Publicación: Novon 2(4): 383. 1992.

Colección tipo: H. Ruiz \& J. Pavón s.n.

Herbarios: MA.

Nombre común: Antaraura, sangre de toro, shucullmay.

Registro departamental: AR, LI, LL.

Regiones Ecológicas: D ST, MA; 500$2550 \mathrm{~m}$.

SINAN PE: Sin registro.

Herbarios peruanos: MOL (5), USM (3).

Observaciones: Este arbusto se conoce de localidades naturalmente fragmentadas y con vegetación marcadamente estacional, en la costa desértica y ladera de la vertiente del Pacífico. Mione \& Coe (1992) indicaron que la mayoría de las colecciones provenían de 1943, pero otros ejemplares depositados en herbarios peruanos adicionan registros recientes de esta especie. D os poblaciones, Mangomarca y Cerro Jerónimo (Amancaes), vecinas a la ciudad de Lima, han desaparecido por la creciente expansión urbana o no han vuelto a ser observadas.

\section{Jaltomata aypatensis S. Leiva, Mione \& Quipuscoa}

\section{DD}

Publicación: Arnaldoa 5(2): 180-181, f. 1. 1998.

Colección tipo: S. Leiva et al. 2022

Hembarios: CCSV, CONN, F; $\underline{\mathrm{HAO}} \underline{\text { !. }}$

Nombre común: D esconocido.

Registro departamental: PI.

Regiones Ecológicas: MA; $2660 \mathrm{~m}$.

SINAN PE: Sin registro.

Hemarios penuanos: HAO (holotipo+1).

Observaciones: Esta especie herbácea se conoce de la cuenca alta del río Quiroz, un área poco herborizada. Los matorrales y fragmentos de bosques, en donde ha sido recolectada, están sujetos a fuerte deforestación y cambios por la actividad agropastoril. No se conoce el tamaño y características de las poblaciones.

\section{Jaltomata bernardelloana S. Leiva \& Mione}

\section{DD}

Publicación: Arnaldoa 5(2): 183-184, f. 2. 1998.

Colección tipo: S. Leiva [1697] 1698

Hembarios: CONN, CORD, F; $\underline{\mathrm{HAO}}$.

Nombre común: Sogorome.

Registro departamental: CA, LL.

Regiones Ecológicas: MA; 3020-3070 m. SINANPE: Sin registro.

Herbarios peruanos: $\mathrm{HAO}$ (holotipo+varias), HUT (2).

Observaciones: Este arbusto se conoce de dos localidades, en la vertiente occidental, en ambientes modificados. Los pobladores locales consumen los frutos. No se conoce el estado actual de sus poblaciones. 


\section{Jaltomata bicolor(Ruiz \& Pav.) Mione \& M.Nee}

\section{LC}

Publicación: Brittonia 45(2): 142. 1993. Colección tipo: H. Ruiz \& J. Pavón s.n. Herbarios: MA.

Nombre común: Antayroma, anataruma, paullo, shucruma, shupiac.

Registro departamental: AN, HV, LI

Regiones Ecológicas: MA, PSH, AA; 2500- $5000 \mathrm{~m}$.

SINAN PE: Sin registro.

Hemarios peruanos: HAO (5), HUT (5), MOL (4), USM (25).

Observaciones: Este arbusto se conoce de varias localidades, en la vertiente occidental del centro del país. La localidad original, en los alrededores de Matucana, conserva todavía la subpoblación original. Por su distribución, continuo registro y rango altitudinal se considera que las amenazas a sus poblaciones son reducidas.

\section{Jaltomata cajacayensis S. Leiva \& Mione}

\section{DD}

Publicación: Novon 10(1): 53-54, f. 1. 2000.

Colección tipo: T. Mione et al. 624

Herbarios: $\mathrm{CONN}$, NY.

Nombre común: D esconocido.

Registro departamental: AN.

Regiones Ecológicas: MA; $2540-2600 \mathrm{~m}$.

SINANPE: Sin registro.

Herbarios penuanos: HAO (2), HUT (1).

Observaciones: Este arbusto se conoce solamente de la vertiente occidental, de la Provincia de Bolognesi en la cuenca del río Fortaleza. Según Mione et al. (2000) aparentemente común en la zona, donde las hojas y los frutos son consumidos localmente. Se desconoce el estado de sus poblaciones.

\section{Jaltomata cajamarca Mione}

\section{EN, B 1ab(iii)}

Publicación: Novon 6(3): 281. 1996

Colección tipo: A. Sagástegui A. 14389

Herbarios: CONN, F; HAO !

Nombre común: Canamuela (fr).

Registro departamental: CA.

Regiones Ecológicas: MDE, MA; 1500_ $2500 \mathrm{~m}$.

SINANPE: Sin registro.

Herbarios penuanos: HAO (isotipo+16), HUT (8), USM (1).

Observaciones: Esta especie subarbustiva se conoce solamente de laderas semixéricas, en la cuenca del río Chicama. Al igual que otras especies en el género, presenta frutos comestibles. Amenazas a sus poblaciones están asociadas a las actividades agro-pastoriles.

\section{Jaltomata cuyasensis S. Leiva, Quipuscoa \& Sawyer}

$$
\text { CR, Blab(i,iii) }
$$

Publicación: Arnaldoa 5(2): 186, 188, f. 3. 1998.

Colección tipo: V. Q uipuscoa et al. 725

Herbarios: CCSV, CONN, CORD, F, MO ;

HAO!, HUT!.

Nombrecomún: Frutilla, uvilla, mortiño blanco.

Registro departamental: PI.

Regiones Ecológicas: MA; 2420-2680 m.

SINAN PE: Sin registro.

Herbarios penuanos: HAO (holotipo+4),

HUT (isotipo+2).
Observaciones: Esta especie subarbustiva se conoce solamente de la cuenca alta del río Chira. Las poblaciones conocidas ocupan fragmentos de bosques montanos occidentales, que como el Bosque de Cuyas, están amenazado por la deforestación y los incendios asociados a esta actividad y a la agricultura.

\section{Jaltomata diversa (J.F. Macbr.) Mione}

\section{NT}

Publicación: Brittonia 51(1): 32. 1999.

Colección tipo: A. Weberbauer 6853

Hemarios: F, GH, NY; MOL!

Nombre común: Desconocido.

Registro departamental: AP, AR, AY, CU. Regiones Ecológicas: MA; 2897-3700 m. SINANPE: RNPG

Herbarios peruanos: MOL (isotipo), USM (2).

Observaciones: Esta especie arbustiva se conoce de varias localidades en el surdel país, principalmenteen lavertientedel Pacífico yen localidades aisladas en vallesinterandinos. Elárea de presencia deesta especiealcanza aproximadamente $450 \mathrm{~km}^{2}$. Al parecer, no ha vuelto a ser recolectado desde 1962. Las amenazas potenciales provienen de la expansión de las actividades agro-pastoriles.

\section{Jaltomata hunzikeri Mione}

$$
\text { CR, Blab(iii) }
$$

Publicación: Rhodora 102(912): 385388, f. 1. [2001] 2000.

Colección tipo: H.E. Stork et al. 9228

Hemarios: G, GH, K, MO.

Nombre común: D esconocido.

Registro departamental: LI.

Regiones Ecológicas: DST; 300 m.

SINAN PE: Sin registro.

Herbarios peruanos: Ninguno.

Observaciones: Esta especie subarbustiva se conoce solamente de una localidad, recolectada en 1938. Al igual que otras especies de lomas, las poblaciones están aisladas y no hay datos adicionales sobre las condiciones del hábitat.

\section{Jaltomata lezamae S. Leiva \& Mione \\ EN, Blab(iii)}

Publicación: Amaldoa 6(1): 66, 69, f. 1. 1999. Colección tipo: A. Sagástegui A. \& S. Leiva 15524

Hemarios: CCSU, F; HAO!

Nombre común: Desconocido.

Registro departamental: CA.

Regiones Ecológicas: MA; 2300-2750 m.

SINANPE: Sin registro.

Herbarios penuanos: HAO (holotipo+9), HUT (1).

Observaciones: Esta especie herbácea se conoce solamente de la vertiente del Pacífico. La mayonía de los registros provienen de una sola localidad, ubicada cerca de los fragmentos de bosque de la vertiente occidental. Amenazas potenciales a las poblaciones de esta especie provienen de los incendios intencionales y la deforestación. 
38. Jaltomata lomana Mione \& S. Leiva

$$
\text { CR, Blab(iii) }
$$

Publicación: Novon 10(1): 54, f. 2. 2000.

Colección tipo: H.E. Stork et al. 9183

Herbarios: G, GH, K.

Nombre común: D esconocido.

Registro departamental: AN.

Regiones Ecológicas: D ST; 450-630 m.

SINANPE: Sin registro.

Herbarios penuanos: HAO (1).

Observaciones: Esta especie arbustiva fue descrita de un ejemplar recolectado en 1938, en las lomas de Mongón y vuelto a registrar 60 años después. Amenazas a sus poblaciones están asociadas con la expansión de la actividad pecuaria, especialmente de granjas avícolas.

\section{Jaltomata mionei S. Leiva \& Quipuscoa}

$$
\text { EN, Blab(iii) }
$$

Publicación: Arnaldoa 5(2): 188-189, 191, f. 4. 1998.

Colección tipo: S. Leiva 1691

Hemarios: CCSV, CONN, CORD, F, MO; HAO!, HUT!, USM?.

Nombre común: D esconocido.

Registro departamental: LL.

Regiones Ecológicas: DST, MDE, MA; 800- $2680 \mathrm{~m}$.

SINAN PE: Sin registro.

Herbarios peruanos: $\mathrm{HAO}$ (holotipo, isotipo), HUT (isotipo+1), USM (isotipo+1)?.

Observaciones: Esta especie herbácea, de frutos comestibles, fue descrita en 1998. O cupaun amplio rango altitudinal y podńa ser anual en los ambientes semixéricos. Probablemente la actividad pecuaria podría considerarse una amenaza para las poblaciones de esta especie.

40. Jaltomata paneroi Mione \& S. Leiva

$$
\text { CR, Blab(iii) }
$$

Publicación: Rhodora 99(900): 283, 285-286, f. 1. 1997.

Colección tipo: J.L. Panero et al. 854

Herbarios: CONN.

Nombre común: D esconocido.

Registro departamental: CA.

Regiones Ecológicas: MA, PAR; 2900$3520 \mathrm{~m}$.

SINAN PE: Sin registro.

Herbarios penuanos: CPUN (1), HAO (2), HUT (2).

Observaciones: Esta especie arbustiva se conoce solamente de la cuenca alta del río Cajamarca. Aparentemente, está restringida a la zona de Kumulca. Produce frutos comestibles durante la estación seca. Probablemente las actividades relacionadas con la agricultura y la minería puedan afectar las poblaciones de esta especie restringida.
41. Jaltomata propinqua (Miers) Mione \& M. Nee

\section{NT}

Publicación: Brittonia 45(2): 143. 1993.

Colección tipo: A. Mathews 774

Herbarios: $\mathrm{K}, \mathrm{W}$.

Nombre común: D esconocido.

Registro departamental: LI.

Regiones Ecológicas: MDE, MA; 1800-

$3000 \mathrm{~m}$.

SINANPE: Sin registro.

Hemarios peruanos: HAO (1), USM (7)?.

Observaciones: Esta especie subarbustiva se conoce solamente de las cuencas medias de los ríos Rímac y Chillón; en ambos valles, ha sido recolectada en forma consecutiva desde el siglo XIX. Crece en condiciones ambientales diversas, todas ellas modificadas. La base de datos TROPICOS cita para esta especie un ejemplar de Colombia, pero esta aparente disyunción no ha sido evaluada.

\section{Jaltomata sagasteguii Mione}

\section{NT}

Publicación: Novon 6(3): 281. 1996.

Colección tipo: A. Sagástegui A. 14388

Herbarios: F; HAO!

Nombre común: Canamuela.

Registro departamental: CA, LL.

Regiones Ecológicas: MA; 2500-3000 m.

SINANPE: Sin registro.

Hemarios penuanos: HAO (isotipo+14), HUT (9), USM (1).

Observaciones: Esta especie subarbustiva, de frutos comestibles, se conoce solamente dela cuenca media del río Chicama. Numerosos ejemplares de herbario representan esta especie que parece ser localmente frecuente. El área de de presencia es de aproximadamente $600 \mathrm{~km}^{2}$. Probablemente se encuentre en otras áreas de la cuenca.

\section{Jaltomata salpoensis S. Leiva \& Mione}

\section{NT}

Publicación: Arnaldoa 6(1): 69, 71-72, f. 2. [2000] 1999 .

Colección tipo: S. Leiva 1724

Herbarios: CCSU, CORD, F; $\mathrm{HAO}$ !.

Nombre común: Desconocido.

Registro departamental: CA, LL.

Regiones Ecológicas: PAR; 3000-3700 m. SINAN PE: Sin registro.

Herbarios peruanos: HAO (holotipo+5), HUT (3).

Observaciones: Esta especie herbácea se conoce de la cuenca alta delos ríos Chicamay Moche, donde es localmente común; el área de presencia alcanza aproximadamente $700 \mathrm{~km}^{2}$. Se la categoriza como casi amenazada. Probablemente mayor exploración en lajalca peruana contribuya a evaluar mejor esta especie.

44. Jaltomata umbellata (Ruiz \& Pav.) Mione \& M. N ee VU, B lab(iii)

Publicación: Brittonia 45(2): 144. 1993.

Colección tipo: J. D ombey s.n.

Herbarios: P.

Nombre común: D esconocido.

Registro departamental: CA, LL, LI.

Regiones Ecológicas: D ST, MA; 150$3050 \mathrm{~m}$.

SINANPE: RNL

Herbarios peruanos: HAO (1), USM (10). 
Observaciones: Esta especie arbustiva se conoce de varias localidades en la costa norte y centro, con un registro de la vertiente Pacífica, siendo el área de presencia de aproximadamente $400 \mathrm{~km}^{2}$. Sus poblaciones se hallan naturalmente fragmentadas y recolecciones contínuas sugieren que en algunas de estas se hallan en condiciones buenas. Amenazas provienen de la expansión urbana y agrícola en la costa centro y norte.

\section{Jaltomata ventricosa (Baker) Mione}

\section{LC}

Publicación: Brittonia 45(2): 141. 1993.

Colección tipo: Anónimo Baker, t. 208

Herbarios:

Nombre común: Callay, songorome.

Registro departamental: LL.

Regiones Ecológicas: MA; 2500-3470 m.

SINAN PE: Sin registro.

Herbarios peruanos: HAO (20), HUT (7), USM (2).

Observaciones: Especie arbustiva vistosa, conocida de ambientes ruderales en la cuenca media del río Moche. Los frutos anaranjados a la madurez se consumen localmente. No se conoce de amenazas directas a las poblaciones de esta especie. Se considera que está casi amenazada por el área reducida de su presencia, aproximadamente $400 \mathrm{~km}^{2}$, además de no encontrarse representada en el sistema de áreas protegidas.

\section{Jaltomata weberbauen (Dammer) Mione \& F.G. Coe}

$$
\text { VU, B lab(iii) }
$$

Publicación: Novon 2(4): 383. 1992.

Colección tipo: A. Weberbauer 2657

Herbarios: B; MOL!.

Nombre común: Cunqui, tomatito.

Registro departamental: AN, LL.

Regiones Ecológicas: MA, PSH; 3300$3840 \mathrm{~m}$.

SINAN PE: Sin registro.

Herbarios penuanos: HAO (2), HUT (2), MOL (isotipo), USM (1).

Observaciones: Esta especie subarbustiva está restringida a la vertiente del Pacífico, en las cuencas de los ríos Chicama, Fortaleza, Huarmey y Tablachaca. El área de presencia se calcula en $300 \mathrm{~km}^{2}$. Como otras especies delazona mesoandina, las amenazas potenciales a sus poblaciones provienen de la actividad agro-pastoril.

\section{Jaltomata whalenii S. Knapp, Mione \& Sagást. CR, B 1ab(iii)}

Publicación: Brittonia 43(3): 181. 1991. Colección tipo: A. Sagástegui A. et al. 12471

Hembarios: IBE, MO, NY; $\underline{\text { HUT! }}$.

Nombre común: D esconocido.

Registro departamental: CA.

Regiones Ecológicas: MDE; $1300 \mathrm{~m}$.

SINAN PE: Sin registro.

Herbarios penuanos: HUT (holotipo+1).

Observaciones: Esta especie subarbustiva se conoce solamente de una localidad ubicada en la vertiente del Pacífico. Knapp et al. (1991) mencionaron los intentos infructuosos por ubicar individuos de esta especie en la localidad original. Por el caracter de su hábitat sujeto a modificaciones abruptas asociadas a las lluvias estacionales, una amenaza potencial estaría asociada al clima. Por su rango de presencia tan reducido permite categorizar esta especie como crítica.

\section{Jaltomata yungayensis Mione \& S. Leiva}

\section{VU, Blab(iii)}

Publicación: Novon 10(1): 58-59, f. 3. 2000.

Colección tipo: T. Mione et al. 628

Hemarios: CONN, NY; MOL.

Nombre común: D esconocido.

Registro departamental: AN.

Regiones Ecológicas: MA, PSH, AA; 2138-4150 m.

SINAN PE: PNH

Herbanios penuanos: HAO (3), HUT (12), MOL (isotipo citado).

Observaciones: Esta especie subarbustiva se conoce de varias localidades, en y alrededores del Parque Nacional Huascarán, en la cuenca del río Santa. El área de presencia es de aproximadamente $120 \mathrm{~km}^{2}$. Incendios intencionales podrían afectar sus poblaciones.

\section{Larnax cuyacensis Sawyer \& S. Leiva}

\section{NE}

Publicación: Novon 11(4): 462. 2001.

Colección tipo: N.W. Sawyer 797

Herbarios: CONN, HAO, MO, NY; $\underline{\mathrm{HAO}}$.

Nombre común: D esconocido.

Registro departamental: PI.

Regiones Ecológicas: BPM; 2400- 2600

m.

SINANPE: Sin registro.

Hemarios penuanos: HAO (isotipo).

Observaciones: Esta especie arbórea o arbustiva se conoce solamente de la vertiente del Pacífico, muy cerca al límite con Ecuador. Junto con L arnax glabra y L . sylvarum forma un complejo que se extiende de Costa Rica al norte del Perú. Se requiere aclarar el estatus taxonómico y el rango de esta especie. Leiva et al. (2006) recientemente han transferido esta especie al género $\mathrm{D}$ eprea.

\section{Lamax grandiflora Sawyer \& S. Leiva}

\section{CR, Blab(iii)}

Publicación: Novon 11(4): 463, 466, f. 3. 2001.

Colección tipo: N.W. Sawyer 827

Henbarios: CONN, HAO, MO, NY; $\underline{\mathrm{HAO} .}$

Nombre común: D esconocido.

Registro departamental: CA.

Regiones Ecológicas: BMHM; 1700$1860 \mathrm{~m}$

SINAN PE: Sin registro.

Herbarios peruanos: HAO (isotipo+1), HUT (1).

Observaciones: Esta especie arbustiva se conoce solamente de una localidad en la cuenca del río Tabaconas; esta población consiste de unos pocos individuos en una de las áreas más amenazadas por la deforestación, por lo que se la considera amenazada. 


\section{Lamax kann-rasmussennionumS. Leiva\& Quipuscoa}

DD

Publicación: Arnaldoa 9(1): 29-30, 32, f. 1, como «kan-rasmussenii». 2002. Colección tipo: S. Leiva \& V. Quipuscoa 2470

Herbarios: AAU, CORD, F, LP, M, MO, NY, Q, QCA; HAO, HUT, USM.

Nombre común: D esconocido.

Registro departamental: SM.

Regiones Ecológicas: BMHM; 1850$1860 \mathrm{~m}$.

SINANPE: Sin registro.

Herbarios peruanos: HAO (holotipo citado+2), HUT (isotipo citado+3), USM (isotipo citado).

Observaciones: Esta especie subarbustiva se conoce solamente de una localidad, ubicada en la cuenca alta del río Saposoa, un tributario del río Huallaga. Al parecer, está presente en bosques montanos parcialmente modificados. Se desconoce el estado de sus poblaciones.

\section{Lamax longipedunculataS. Leiva, E. Rodr. \& J. Campos}

\section{CR, Bla}

Publicación: Arnaldoa 5(2): 194-195, 197, f. 1. 1998.

Colección tipo: S. Leiva et al. 2098

Herbarios: CONN, CORD, F, M, MO; HAO!, HUT!.

Nombre común: D esconocido.

Registro departamental: CA.

Regiones Ecológicas: BMHM; 1700$1940 \mathrm{~m}$.

SINAN PE: Sin registro.

Herbarios penuanos: HAO (holotipo+1), HUT (isotipo+3), USM (1).

Observaciones: Sawyer (2001), sobre la base del examen del ejemplar tipo de esta especie y de L arnax macrocalyx, reconoce a L . longipedunculata incluyendo hierbas y arbustos. Sus poblaciones provienen de una sola localidad en la cuenca del río Tabaconas, en diferentes tipos de ambientes ecológicos. No se conoce de amenazas a esta especie, pero no cuenta con poblaciones protegidas.

\section{Larnax lutea S. Leiva}

\section{EN, Bla}

Publicación: Arnaldoa 4(1): 19, 21, f. 2. 1996.

Colección tipo: S. Leiva et al. 1385

Herbarios: CONN, CORD, F, MO; $\underline{\mathrm{HAO} \text { !. }}$

Nombre común: D esconocido.

Registro departamental: AM, CA, HU.

Regiones Ecológicas: $\mathrm{MA}, \mathrm{BMHM}$; $1800-2500 \mathrm{~m}$.

SINANPE: ZRCC

Hembarios penuanos: HAO (holotipo).

Observaciones: Esta especie subarbustiva se conoce de localidades dispersas, en las cuencas del Chotano y Huallaga. Más de $350 \mathrm{~km}$ en línea recta separan las localidades más extremas, aunque no hay recolecciones adicionales entre estas. Una de las poblaciones se encuentra en la Zona Reservada Cordillera Colán.

\section{Larnax nieva S. Leiva \& P. Lezama}

DD

Publicación: Arnaldoa 10(1): 106-107, 108, f. 1. 2003.

Colección tipo: S. Leiva \& N. Sawyer 2045

Herbarios: CCSS, F, NY; HAO, HUT.

Nombre común: D esconocido.

Registro departamental: AM, CA.

Regiones Ecológicas: BMHM; 1500$2050 \mathrm{~m}$.

SINAN PE: Sin registro.

Hemarios penuanos: HAO (holotipo+4), HUT (isotipo).

Observaciones: Esta especie arbustiva se conoce de dos localidades, una en la cuenca alta del nío Mayo y la otra en la del Canchis en el límite con Ecuador. Leiva \& Lezama (2003) señalan que esta especie es localmente abundantey no observaron amenazas a sus poblaciones. Probablemente existan poblaciones en Ecuador.

\section{Larnax parviflora Sawyer \& S. Leiva}

\section{NE}

Publicación: Novon 11(4): 466, 468, f. 4. 2001.

Colección tipo: M.O. Dillon et al. 6141

Herbarios: F; HAO.

Nombre común: D esconocido.

Registro departamental: CA.

Regiones Ecológicas: BMHM; 2350$2650 \mathrm{~m}$.

SINANPE: PNC

Herbarios peruanos: HAO (isotipo).

Observaciones: Esta especie recientemente reconocida tiene afinidad con la especie endémica ecuatoriana L arnax psilophyta y de la cual se diferencia por su porte mayor, flores amarillas en lugar de verdes y los pedicelos de los frutos de menor tamaño. Aparentemente restringida a los alrededores del Parque Nacional Cutervo.

\section{Larnax purpurea S. Leiva}

\section{LC}

Publicación: Arnaldoa 4(1): 16, f. 1. 1996. Colección tipo: S. Leiva et al. 1560

Herbarios: CONN, CORD, F, MO, NY; HAO!, HUT!.

Nombre común: D esconocido.

Registro departamental: AM, CA, SM.

Regiones Ecológicas: $\mathrm{BMHM}, \mathrm{BMHP}$, BHA; 250- $1940 \mathrm{~m}$.

SINANPE: Sin registro.

Hembarios penuanos: HAO (holotipo+3), USM (1).

Observaciones: Especie herbácea conocida de numerosas colecciones del norte del país, en donde es aparentemente común, en las cuencas del Mayo y Marañón. Presenta un rango ecológico amplio. Podría estar representada en la flora ecuatoriana (Jørgensen \& León Yánez, 1999). 


\section{Larnax sagasteguii S. Leiva, Q uipuscoa \& Sawyer}

$$
\text { EN, Bla }
$$

Publicación: Arnaldoa 5(1): 86, 88-89, f. 2. 1998.

Colección tipo: V. Q uipuscoa et al. 601

Hembarios: CONN, CORD, F, MO; $\underline{\mathrm{HAO} \text { !, }}$

HUT!.

Nombre común: Suburrión.

Registro departamental: PI.

Regiones Ecológicas: BMHM; 2500-

$3100 \mathrm{~m}$.

SINAN PE: Sin registro.

Herbarios penuanos: HAO (holotipo+4),

HUT (isotipo+1).

Observaciones: Esta especie arbustiva se conoce solamente del norte del país, en la cuenca alta del río Quiroz. Las dos localidades conocidas cuentan con bosques fragmentados, por la deforestación y expansión agrícola. Esta especie podría hallarse en Ecuador. Leiva et al. (1998) indicaron que tiene frutos comestibles de potencial comercial. No se conoce el volumen de cosecha de frutos ni su impacto en las poblaciones.

\section{Lamax sawyeniana S. Leiva, E. Rodr. \& J. Campos}

\section{DD}

Publicación: Arnaldoa 5(2): 203-204, 206, f. 4. 1998.

Colección tipo: S. Leiva et al. 2097

Herbarios: CONN, CORD, F, M, MO; HAO!, HUT!.

Nombre común: D esconocido.

Registro departamental: CA.

Regiones Ecológicas: BMHM; 1700$1940 \mathrm{~m}$.

SINAN PE: Sin registro.

Herbarios penuanos: HAO (holotipo+1), HUT (isotipo), USM (1).

Observaciones: Esta especie herbácea se conoce de unas pocas poblaciones, en la cuenca del río Tabaconas. A parentemente, ocupa ambientes modificados y parcialmente abiertos, sin embargo no hay información adicional sobre el tamaño de las poblaciones.

\section{Larnax schjellerupiae S. Leiva \& Quipuscoa}

\section{DD}

Publicación: Arnaldoa 9(1): 32-34, como «schjellerupii». 2002.

Colección tipo: S. Leiva \& V. Quipuscoa 2479

Hembanios: AAU, F; HAO, HUT!

Nombre común: D esconocido.

Registro departamental: SM.

Regiones Ecológicas: BMHM; $2000 \mathrm{~m}$.

SINAN PE: Sin registro.

Herbarios peruanos: HAO (holotipo), HUT (isotipo).

Observaciones: Especie herbácea conocida sólo de la colección tipo, una planta recolectada en 2000, en la cuenca del Saposoa. Se desconoce el estado de sus poblaciones.

\section{Larnax vasquezii S. Leiva, E. Rodr. \& J. Campos}

$$
\text { EN, Blab(iii) }
$$

Publicación: Arnaldoa 5(2): 206-207, 209, f. 5. 1998.

Colección tipo: S. Leiva et al. 2109

Herbarios: CONN, CORD, F, M, MO, US;

HAO!, HUT!, USM!.

Nombre común: D esconocido.

Registro departamental: CA, SM.

Regiones Ecológicas: BMHM; 1600$2040 \mathrm{~m}$.

SINAN PE: Sin registro.

Herbarios peruanos: HAO (holotipo, isotipo), HUT (isotipo), USM (isotipo+1).

Observaciones: Esta especie subarbustiva se conoce de dos poblaciones disyuntas de los bosques montanos orientales en las cuencas del Mayo y Chinchipe. La localidad en San Martín corresponde a los bosques donde habita el mono choro de cola amarilla, otra especie endémica peruana. Amenazas a sus poblaciones están asociadas a la deforestación.

\section{Leptoglossis acutiloba (I.M. Johnst.) Hunz. \&} Subils

\section{EN, Blab(iii)}

Publicación: Lorentzia 3: 17. 1979.

Colección tipo: F.W. Pennell 13063

Hembarios: GH, PH.

Nombre común: D esconocido.

Registro departamental: AR, MO.

Regiones Ecológicas: DST, MDE; 100$2000 \mathrm{~m}$.

SINAN PE: Sin registro.

Herbarios peruanos: Ninguno.

Observaciones: Hierba anual conocida de tres localidades aisladas entre ellas. No ha vuelto a ser recolectada desde la década de 1950. La localidad original ubicada en Tiabaya, probablemente, ha desaparecido por el crecimiento urbano de la ciudad de Arequipa. Se desconoce el impacto de la irrigación Majes a localidades potenciales de esta especie.

\section{Leptoglossis albiflora (I.M. Johnst.) H unz. \& Sublis} VU, Bla

Publicación: Bot. Mus. Leafl. 27: 19. 1979. Colección tipo: A. Weberbauer 7424a

Hembarios: BM, GH.

Nombre común: D esconocido.

Registro departamental: AN, HV, IC, LI, MO.

Regiones Ecológicas: MDE; 1800- 2000 m.

SINAN PE: Sin registro.

Herbarios peruanos: USM (3).

Observaciones: Esta especie herbácea, probablemente anual, se conoce solamente de la vertiente occidental, en las cuencas medias de los ríos Nepeña, Rímac, Pisco y Torata. No hay recolectas recientes de esta especie, tal vez por su hábito anual y la escasa herborización en ambientes xéricos. Amenazas potenciales provendrían de la transformación de estos valles por expansión urbana y agrícola. 
63. Leptoglossis dancyana H unz. \& Sublis

$$
\text { VU, Bla }
$$

Publicación: Lorentzia 3: 15. 1979.

Colección tipo: R. Zegarra 271

Herbarios: US.

Nombre común: D esconocido.

Registro departamental: AR, TA.

Regiones Ecológicas: D ST; 400-900 m.

SINAN PE: Sin registro.

Hemarios penuanos: HUT (3), USM (7).

Observaciones: Planta anual conocida solamente de poblaciones fragmentadas. Al parecer, todos los ejemplares de esta especie fueron recolectados durante eventos El Niño, cuando alcanza a ser localmente abundante, como se observó en 1983. Las colecciones de Arequipa provienen de las lomas de Camaná, una de las más importantes en el sistema de vegetación de oasis.

\section{Leptoglossis ferreyraei Hunz. \& Sublis}

$$
\text { EN, Blab(iii) }
$$

Publicación: Bot. Mus. Leafl. 27(1-2): 16. [1980] 1979.

Colección tipo: R. Ferreyra 14020

Hembarios: ; USM.

Nombre común: Desconocido.

Registro departamental: AR.

Regiones Ecológicas: DST; 150-900 m.

SINAN PE: Sin registro.

Hemanios penuanos: HAO (1), HUT (1), USM (holotipo?+7).

Observaciones: Esta hierba se conoce de dos localidades naturalmente fragmentadas. La mayor parte de las recolectas han sido realizadas durante eventos El Niño. Ninguno de los ambientes de lomas del sur del país está representado en el sistema de áreas protegidas. Amenazas a las poblaciones están asociadas a modificación del hábitat por actividad industrial.

\section{Leptoglossis lomana (Diels) Hunz.}

$$
\text { EN, Blab(iii) }
$$

Publicación: Kurtziana 10: 46. 1977. Colección tipo: A. Weberbauer 1486 Herbarios: B.

Nombre común: D esconocido.

Registro departamental: AR, MO, TA. Regiones Ecológicas: D ST, MDE; 15$800 \mathrm{~m}$.

SINAN PE: Sin registro.

Herbarios peruanos: USM (5).

Observaciones: Esta especie anual se conoce de varias localidades en el surdel país. Suspoblaciones están naturalmentefragmentadasyninguna está representada en alguna de las áreas protegidas. Amenazas a las poblaciones están asociadas a modificación del hábitat.

\section{Leptoglossis schwenckioides Benth.}

\section{LC}

Publicación: Bot. Voy. Sulphur 143. 1844. 1844.

Colección tipo: G.W. Barclay s.n.

Herbarios: $\mathrm{K}$.

Nombre común: D esconocido.

Registro departamental: AN, CA, LI.

Regiones Ecológicas: D ST, MDE; 350$2500 \mathrm{~m}$.

SINANPE: Sin registro.

Herbarios penuanos: HAO (1), HUT (5), MOL (1), USM (10).
Observaciones: Estaespeciesubarbustivaseconocedevariaslocalidades en el nortey centro de las vertientes occidentales, siendo las poblaciones mejor representadas, las de las cuencas del Rímac y Chillón.

\section{Lycianthes jelskii (Zahlbr.) Bitter}

\section{NT}

Publicación: D ie Gattung Lycianthes 399. 1919.

Colección tipo: C. Jelski 47

Herbarios: B.

Nombre común: D esconocido.

Registro departamental: CA, LA.

Regiones Ecológicas: MDE, MA; $1200-$ $2500 \mathrm{~m}$.

SINANPE: Sin registro.

Herbarios peruanos: $\mathrm{HAO}$ (5).

Observaciones: Esta especie endémica no fue reconocida como tal por Brako \& Zarucchi (1993). D esde fines de la década de 1980, se han registrado nuevas poblaciones, todas localizadas en las vertientes occidentales, las que ocupan ambientes muy modificados por actividad humana.

\section{Nicotiana benavidesii Goodsp.}

$$
\text { VU, B lab(iii) }
$$

Publicación: Univ. Calif. Publ. Bot. 18: 137, pls. 9, 10, 12a. 1938.

Colección tipo: J. West 3797

Herbarios: G, NY, UC, US.

Nombre común: Coamasaya.

Registro departamental: AP, CU.

Regiones Ecológicas: MA; 1850-3500 m.

SINAN PE: Sin registro.

Herbarios penuanos: CUZ (1), MOL (1), USM (4).

Observaciones: Esta especie subarbustiva, nombrada en honor del Presidente O.R. Benavides, se conoce de varias poblaciones principalmente en la cuenca media del río A purímac y sus tributarios, el Limatambo y Pachachaca, así como en la cuenca del Urubamba, asociado a matorrales. Ha sido recolectado desde la década de 1930. Amenazas potenciales a sus poblaciones podrían estar asociadas a modificación del hábitat por incendios intencionales y expansión urbana.

\section{Nicotiana knightiana Goodsp.}

$$
\text { EN, Blab(iii) }
$$

Publicación: Univ. Calif. Publ. Bot. 18: 139, t.11, 12b. 1938.

Colección tipo: Y. Mexia 4161

Herbarios: MO, NY, UC, US.

Nombre común: Tabaquilla.

Registro departamental: AR.

Regiones Ecológicas: D ST; 300-600 m.

SINAN PE: Sin registro.

Herbarios peruanos: Ninguno.

Observaciones: Esta especie anual se conoce solamente del sur del país, si bien Brako \& Zarucchi (1993) no la reconocieron como endémica e indicaron erróneamente un rango departamental mayor. No se conoce de recolectas recientes, ni de registro en áreas protegidas. Poco se sabe del tamaño de sus poblaciones en las localidades conocidas. Sin embargo, por ser una planta anual, cambios asociados a modificaciones del hábitat podrían amenazar a esta especie. 


\section{Nicotiana paniculata L.}

\section{LC}

Publicación: Sp. Pl. 1: 180. 1753.

Colección tipo: J. Jussieu s.n.

Herbarios: P.

Nombre común: Puille; tabaco cimmarrón; tabaco silvestre.

Registro departamental: AN, AR, AY, CA, IC, JU, LA, LL, LI, MO.

Regiones Ecológicas: DST, MDE; $120-$ $2800 \mathrm{~m}$.

SINAN PE: Sin registro.

Herbarios penuanos: HAO (6), USM (45).

Observaciones: Planta anual conocida de varias localidades, principalmente en la costa central y partes bajas de la vertiente occidental. Por la amplitud de su distribución y la buena representación en los herbarios sela reconoce como de Preocupación Menor.

\section{Nicotiana raimondiij.F. Macbr.}

\section{VU, B lab(iii)}

Publicación: Publ. Field Columbian Mus., Bot. Ser. 8(2): 106. 1930.

Colección tipo: F. Herrera 1540

Herbarios: $F$.

Nombre común: D esconocido.

Registro departamental: CU.

Regiones Ecológicas: MA; 2750-3100 m.

SINANPE: Sin registro.

Herbarios peruanos: USM (2).

Observaciones: Esta especie arbustiva se conoce de varias poblaciones, ubicadas todas en la cuenca del río Urubamba, donde habita matorrales, ocasionalmente sujetos a incendios intencionales o degradados por su cercanía a caminos.

\section{Nicotiana setchelliiGoodsp.}

\section{EN, Bla}

Publicación: Univ. Calif. Publ. Bot. 18: 195, pls. 14, 15. 1941

Colección tipo: P.C. Hutchison ex Hort. (UC 639057) s.n.

Herbarios: UC.

Nombre común: Atcho-tabaco.

Registro departamental: AM.

Regiones Ecológicas: $\mathrm{MA}, \mathrm{BMHM}$; 1800-3000 m.

SINANPE: Sin registro.

Herbarios peruanos: USM (isotipo+7).

Observaciones: Esta especie arbustiva se conoce de matorrales y ambientes ecotonales del bosque montano húmedo y ambientes semixéricos, en la vertiente oriental, en el norte del país. Todas las poblaciones provienen de la cuenca del río Utcubamba. Las semillas de esta especie fueron originalmente recolectadas por Beauchamp y luego germinadas en el invernadero de la Universidad de California; una de las plantas sirvió para su descripción formal. Goodspeed (1954) consideró esta especie con potencial ornamental, pero aparentemente no ha sido ingresada al mercado para este fin, más bien se emplea en la investigación de la evolución del género.

\section{Nicotiana thyrsiflora Goodsp.}

$$
\text { VU, B1ab(iii) }
$$

Publicación: Univ. Calif. Publ. Bot. 18: 138, t.13. 1938.

Colección tipo: A. Weberbauer 7015

Herbarios: B, F, GH; MOL!.

Nombre común: Seile; tabaco inca; tabaco silvestre.

Registro departamental: AN, CA, LL, PI. Regiones Ecológicas: PSH, PAR; 2900$4400 \mathrm{~m}$.

SINANPE: PNH

Herbarios peruanos: CPUN (1); MOL (isotipo), USM (9).

Observaciones: Esta especie arbustiva se conoce de varias localidades, en ambientes de jalca y de puna, donde localmente se halla en grupos de 20 a 30 individuos dispersos. Al igual que otras especies de matorrales, amenazas potenciales a sus poblaciones provienen de modificación del hábitat por incendios intencionales. Las poblaciones más distantes entre ellas se encuentran a más de $500 \mathrm{~km}$ de distancia.

\section{Nolana arenicola I.M. Johnst.}

$$
\text { VU, B 1ab(iii) }
$$

Publicación: Contr. Gray Herb. 112: 29. 1936.

Colección tipo: E. Werdermann 730

Herbarios: B, BM, F, G, HG, K, NY, S, SI, U, UC, US.

Nombre común: D esconocido.

Registro departamental: AR, MO, TA.

Regiones Ecológicas: D ST; 200-900 m.

SINAN PE: Sin registro.

Herbarios peruanos: HAO (1), USM (20).

Observaciones: Esta especie anual se conoce de menos de cinco localidades, naturalmente fragmentadas. La mayoría de los registros provienen de las lomas de Sama en Tacna. Mesa (1997) indicó su presencia en la flora chilena, probablemente de Arica. Sin embargo, Tago-Nakazawa \& Dillon (1999) la restringen solamente al Perú. Los ambientes de lomas en el sur del país no reciben protección alguna y en algunos casos pueden estar afectados por las actividades industriales y mineras.

\section{Nolana aticoana Ferreyra}

\section{EN, Blab(iii)}

Publicación: Publ. Mus. Hist. Nat. «Javier Prado» Ser. B, Bot. 10: 13-14, t. 9. 1955.

Colección tipo: R. Ferreyra 2524

Hemanios: GH, USM; USM!.

Nombre común: D esconocido.

Registro departamental: AR.

Regiones Ecológicas: D ST; $10-600 \mathrm{~m}$.

SINANPE: Sin registro.

Herbarios peruanos: HAO (1), USM (holotipo+13).

Observaciones: Especie subarbustiva conocida solamente de dos localidades, en el norte de Arequipa, separadas por algo menos de $80 \mathrm{~km}$. Las amenazas potenciales a sus poblaciones están asociadas a modificación del hábitat por actividades agrícolas. 


\section{Nolana cerrateana Femeyra}

$$
\text { EN, Bla }
$$

Publicación: Publ. Mus. Hist. Nat. «Javier Prado» Ser. B, Bot. 10: 11-13, t. 8. 1955.

Colección tipo: R. Ferreyra 2558

Herbarios: MO, UC; MOL!, USM!.

Nombre común: D esconocido.

Registro departamental: AR.

Regiones Ecológicas: D ST; 50- $700 \mathrm{~m}$.

SINANPE: Sin registro.

Herbarios peruanos: $\mathrm{HAO}$ (3), MOL (isotipo), USM (holotipo+5).

Observaciones: Planta perenne conocida de tres localidades naturalmente fragmentadasm en la costa de Arequipa. Ha sido recolectada en diferentes años, durante eventos El Niño.

\section{Nolana confinis (I.M. Johnst.) I.M. Johnst.}

\section{EN, Bla}

Publicación: Contr. Gray Herb. 112: 78. 1936.

Colección tipo: A. Weberbauer 7382

Herbarios: F, US.

Nombre común: D esconocido.

Registro departamental: AR, MO, TA.

Regiones Ecológicas: D ST, MA; 200$3000 \mathrm{~m}$.

SINAN PE: Sin registro.

Herbarios peruanos: USM (8).

Observaciones: Esta especie arbustiva presenta un amplio rango altitudinal, característica rara en el género. Fue descrita originalmente de la zona de Candarave en Tacna, de una planta recolectada en 1925. Sin embargo, se conoce sólo de unas cuatro localidades.

\section{Nolana coronata Ruiz \& Pav.}

\section{EN, Blab(iii)}

Publicación: Fl. Peruv. 2: 7, t. 112b. 1799.

Colección tipo: J. Tafalla s.n.

Herbarios: B, F, G, K, MA; USM!.

Nombre común: D esconocido.

Registro departamental: AR.

Regiones Ecológicas: D ST; $50-800 \mathrm{~m}$.

SINANPE: Sin registro.

Herbarios peruanos: HAO (1), USM (isotipo+8).

Observaciones: Especie anual conocida solamente de cuatro localidades, naturalmente fragmentadas, a lo largo de $240 \mathrm{~km}$ en la costa de A requipa. La mayor parte de las recolectas han sido realizadas durante eventos El Niño.

\section{Nolana gayana (Gaudich.) Koch}

\section{VU, Blab(iii)}

Publicación: Index Sem. (Berlin) 1855 (appendix): 12. 1855.

Colección tipo: C. Gay s.n.

Herbarios:

Nombre común: D esconocido.

Registro departamental: AN, LL, LI.

Regiones Ecológicas: DST; 100- $700 \mathrm{~m}$.

SINAN PE: RNL

Herbarios penuanos: HAO (1), MOL (1), USM (31).
Observaciones: Esta especie perenne se conoce de más de cinco localidades, naturalmente fragmentadas, a lo largo de la costa de La Libertad a Lima. Una de las subpoblaciones está en la Reserva Nacional de Lachay. Amenazas a sus poblaciones, fuera de esta área protegida, están relacionadas con la destrucción de hábitat por expansión urbana y contaminación ambiental.

\section{Nolana gracillima (I.M. Johnst.) I.M. Johnst.}

\section{NE}

Publicación: Contr. Gray Herb. 112: 59. 1929.

Colección tipo: A. Weberbauer 7457

Herbarios: GH, US.

Nombre común: D esconocido.

Registro departamental: AR, MO, TA. Regiones Ecológicas: MDE; 800- 2400 m.

SINANPE: Sin registro.

Herbarios peruanos: USM (3).

Observaciones: Esta especie anual se conoce de tres localidades aisladas y xéricas. Mesa (1997) reconoció esta especie para Chile; sin embargo Tago-Nakazawa \& Dillon (1999) la restringen solamente al sur del país de Moquegua a Tacna.

\section{Nolana guentheri I.M. Johnst.}

\section{DD}

Publicación: Contr. Gray Herb. 112: 55. 1936.

Colección tipo: E. Günther \& O. Buchtien 113

Hembarios: GH, HBG.

Nombre común: D esconocido.

Registro departamental: AR.

Regiones Ecológicas: MDE; $1000 \mathrm{~m}$.

SINAN PE: Sin registro.

Herbarios peruanos: Ninguno.

Observaciones: Esta hierba perenne se conoce solamente de una localidad, en la Provincia de Islay en Arequipa. Aparentemente no ha vuelto a ser recolectada desde 1923, aunque podría confundírsele con $\mathrm{N}$ olana humifusa. Se desconoce el estado de sus poblaciones.

\section{Nolana humifusa (Gouan) I.M. Johnst.}

\section{NT}

Publicación: Contr. G ray Herb. 112: 50. 1936.

Colección tipo: Anónimo s.n.

Herbarios: MPU.

Nombre común: D esconocido.

Registro departamental: AN, LL, LI. Regiones Ecológicas: DST; 200- $700 \mathrm{~m}$. SINANPE: RNL

Herbarios penuanos: HUT (2), USM.

Observaciones: Esta especie no fue señalada como endémica por Brako \& Zarucchi (1993), pero aquí se la reconoce como un endemismo. Esta es una especie anual, conocida de poblaciones naturalmente fragmentadas. La mayoría de los registros provienen de la costa de Lima, algunas de estas poblaciones no existen, como en el caso de las que crecían en Cerro San Cristobal, Chorrillos y Barranco, entre otras ubicadas en lugares ocupados por la ciudad de Lima. 


\section{Nolana inflata Ruiz \& Pav.}

\section{EN, Bla}

Publicación: Fl. Peruv. 2: 7, t. 112a. 1799. Colección tipo: J. Tafalla

Herbarios: F, FI, G, K, MA, P.

Nombre común: D esconocido.

Registro departamental: AR.

Regiones Ecológicas: DST, MDE; 5$1500 \mathrm{~m}$.

SINAN PE: Sin registro.

Herbarios penuanos: HAO (2), USM (13).

Observaciones: Esta planta perenne y glandulosa, se conoce de tres localidades naturalmente fragmentadas; una de estas localidades, Atiquipa, ha sido propuesta desde la década de 1940, como una área que merece ser protegida. Sin embargo, ningún ambiente de lomas en el sur del país se encuentra reconocido en el sistema. Amenazas potenciales están asociadas a modificación del hábitat.

84. Nolana insularis (I.M. Johnst.) I.M. Johnst.

$$
\text { CR, Bla }
$$

Publicación: Contr. Gray Herb. 112: 49. 1936. Colección tipo: R.C. Murphy 3472

Hemarios: BKL, GH.

Nombre común: D esconocido.

Registro departamental: IC.

Regiones Ecológicas: D ST; altitud desconocida.

SINANPE: RNP

Herbarios peruanos: Ninguno.

Observaciones: Esta hierba perennelleva como nombre el caracter de su distribución, puesto que se conoce sólo de una de las islas que forman parte de la Reserva Nacional de Paracas. No ha vuelto a ser recolectada desde fines de la década de 1910.

\section{Nolana ivaniana Femeyra}

\section{EN, Bla}

Publicación: Publ. Mus. Hist. Nat. «Javier Prado» Ser. B, Bot. 10: 3-4, t. 1. 1955.

Colección tipo: R. Ferreyra 11564

Hemanios: ; USM!.

Nombre común: D esconocido.

Registro departamental: AR.

Regiones Ecológicas: D ST; $100-200 \mathrm{~m}$.

SINAN PE: Sin registro.

Herbarios peruanos: HAO (1), USM (holotipo+3).

Observaciones: Esta especie anual se conoce solamente de los alrededores de Mollendo.Alparecer, ocupaambientesarenososasociados a neblinas, como también en suelos con altos contenidos en sales.

\section{Nolana johnstonii Vargas}

$$
\text { EN, B1a }
$$

Publicación: Revista Univ. (Cuzco) 43(107): 155, t. 5. 1955.

Colección tipo: C. Vargas C. 8570

Herbarios: GH; CUZ.

Nombre común: Desconocido,

Registro departamental: MO, TA.

Regiones Ecológicas: DST; $50-800 \mathrm{~m}$.

SINAN PE: Sin registro.

Herbarios peruanos: CUZ (holotipo

citado), HAO (2), USM (11).
Observaciones: Esta especie subarbustiva se conoce de cuatro localidades, en el sur del país. Todas las poblaciones están naturalmente fragmentadas y su área no supera los $5000 \mathrm{~km}^{2}$. Al igual que otras especies delosambientes estacionales delomas, lamayonádelas recolectas fueron realizadas durante eventos El Niño.

87. Nolana latipes I.M. Johnst.

$$
\text { EN, Blab(iii) }
$$

Publicación: Contr. Gray Herb. 112: 30. 1936. Colección tipo: A. Weberbauer 1498

Hembarios: GH; USM!.

Nombre común: D esconocido. Registro departamental: AR, LI. Regiones Ecológicas: D ST; 20-400 m. SINANPE: Sin registro.

Herbarios penuanos: USM (isotipo+2).

Observaciones: Hierba anual conocida principalmente de los alrededores de Mollendo en Arequipa, así como de las lomas de Ilo en Moquegua, En 1923, esta especie fue recolectada delos alrededores de Mejía en Arequipa, pero no se conoce de ejemplares recientes. En esta zona la ampliación de la frontera agrícola ha modificado parte del paisaje de ambientes con vegetación efímera a gramadales.

\section{Nolana laxa (Miers) I.M. Johnst.}

$$
\text { EN, Blab(iii) }
$$

Publicación: Contr. Gray Herb. 112: 59. 1936. Colección tipo: H. Ruiz \& J. Pavón s.n. Henbarios: K.

Nombre común: Desconocido.

Registro departamental: LI.

Regiones Ecológicas: D ST; $10-900 \mathrm{~m}$.

SINANPE: Sin registro.

Hembarios peruanos: USM (4).

Observaciones: Plantas anuales conocidas de cuatro localidades, en las Provincias de Limay Canta. Todas las localidades están ubicadas en áreas que hoy están influenciadas por la expansión urbana de Lima. La aparente escasez de colecciones de herbario pueda deberse a la escasa herborización de los ambientes que ocupa esta especie.

\section{Nolana mariarosae Femeyra}

\section{DD}

Publicación: Bol. Soc. Peruana Bot. 7(12): 3- 5. 1974.

Colección tipo: R. Ferreyra 12490

Hembarios: VALP.

Nombre común: D esconocido.

Registro departamental: AR.

Regiones Ecológicas: D ST; 200-300 m.

SINAN PE: Sin registro.

Herbarios peruanos: Ninguno.

Observaciones: Esta especie se conoce solamente de una localidad en Arequipa. No ha vuelto a ser recolectada desde 1957. Se desconoce el estado de sus poblaciones.

\section{Nolana minor Ferreyra}

$$
\text { CR, Blab(iii) }
$$

Publicación: Publ. Mus. Hist. Nat. «Javier Prado» Ser. B, Bot. 10: 4-5, t. 2. 1955.

Colección tipo: R. Ferreyra 2535

Herbarios: K, US; MOL!.

Nombre común: D esconocido.

Registro departamental: AR.

Regiones Ecológicas: D ST; $20-30 \mathrm{~m}$.

SINANPE: Sin registro.

Herbarios peruanos: MOL (isotipo). 
Observaciones: Planta anual, diminuta, conocida de una localidad de lomas, en Arequipa. Mesa (1981) la reconoció como sinónimo de N olana tarapacana subsp. thinophila, pero Macbride (1960) y TagoNakazawa \& Dillon (1999) aceptan a esta especie. No ha vuelto a ser recolectada desde 1947. A parentemente una parte dela localidad original ha sido destruida.

\section{Nolana pallida I.M. Johnst.}

$$
\text { VU, B1ab(iii) }
$$

Publicación: Contr. Gray Herb. 112: 69. 1936.

Colección tipo: A. Weberbauer 7183

Herbarios: $\mathrm{B}(\mathrm{d}), \mathrm{GH}$.

Nombre común: Desconocido.

Registro departamental: AR, IC.

Regiones Ecológicas: D ST; 50-500 m.

SINANPE: Sin registro.

Herbarios penuanos: HAO (1), USM (11).

Observaciones: Especie arbustiva conocida del sur de Ica al sur de Arequipa. Raimondi recolectó esta especie en las lomas de Atiquipa y Atico. Amenazas a sus poblaciones están asociadas a modificación del hábitat ya sea por expansión agrícola o industrial y contaminación ambiental.

\section{Nolana pallidula I.M. Johnst.}

\section{VU, Blab(iii)}

Publicación: Contr. Gray Herb. 112: 31. 1936.

Colección tipo: E. Werdermann 728

Herbarios: B, BM, F, G, GH, K, NY, S, UC, US.

Nombre común: D esconocido.

Registro departamental: AR, IC, MO, TA. Regiones Ecológicas: D ST; 100-900 m. SINANPE: Sin registro.

Herbarios penuanos: HAO (3), USM (12).

Observaciones: Esta especie anual se conoce de cinco poblaciones, naturalmente fragmentadas ubicadas a lo largo de la costa del sur de Ica a Tacna. Algunas de sus poblaciones podrían estar afectadas por contaminación ambiental, como en Moquegua o, por la expansión urbana, como en Tacna.

\section{Nolana pearcei I.M. Johnst.}

\section{DD}

Publicación: Contr. Gray Herb. 112: 58. 1936.

Colección tipo: R.W. Pearce s.n.

Henbarios: BM, K.

Nombre común: D esconocido.

Registro departamental: TA.

Regiones Ecológicas: D ST; altitud desconocida.

SINANPE: Sin registro.

Herbarios peruanos: Ninguno.

Observaciones: Planta anual conocida solamente de una localidad en la costa de Tacna, pero sin detalles de su ubicación. No ha vuelto a ser recolectada desde 1864.
94. Nolana pilosa I.M. Johnst.

$$
\text { VU, B lab(iii) }
$$

Publicación: Contr. Gray Herb. 112: 79. 1936. Colección tipo: E. G ünther \& O. Buchtien 117

Hemanios: HBG.

Nombre común: D esconocido.

Registro departamental: AR, MO.

Regiones Ecológicas: D ST; 100-900 m. SINAN PE: Sin registro.

Hemarios penuanos: HAO (2), MOL (1), USM (14).

Observaciones: Esta especie perenne se conoce de cinco localidades, naturalmente fragmentadas localizadas en Arequipa y Moquegua. Al igual que otras especies en el género, las recolectas fueron realizadas durante eventos «El Niño». En 1986 fue registrada de la localidad original en los alrededores de Mejía, los cuales reciben fuerte impacto por la expansión agrícola.

\section{Nolana platyphylla (I.M. Johnst.) I.M. Johnst.}

\section{DD}

Publicación: Contr. Gray Herb. 112: 60. 1936.

Colección tipo: A. Weberbauer 7455

Herbarios: F, G, GH, K, S, US.

Nombre común: D esconocido.

Registro departamental: MO.

Regiones Ecológicas: MDE; $1550 \mathrm{~m}$.

SINANPE: Sin registro.

Herbarios peruanos: Ninguno.

Observaciones: Planta anual conocida solamente de una localidad, en Arequipa. No ha vuelto a ser recolectada desde 1925.

\section{Nolana plicata I.M. Johnst.}

$$
\text { VU, Blab(iii) }
$$

Publicación: Contr. Gray Herb. 85: 174. 1929.

Colección tipo: A. Weberbauer 7190

Herbarios: $F$.

Nombre común: D esconocido.

Registro departamental: AR, IC.

Regiones Ecológicas: D ST; 250-900 m. SINAN PE: Sin registro.

Herbarios peruanos: HAO (1), MOL (1), USM (19).

Observaciones: Esta especie subarbustiva se conoce de seis localidades naturalmente fragmentadas, ubicadas del sur de Ica a Arequipa. Fue descrita de un ejemplar recolectado en Atiquipa, una de las lomas más diversas en el desierto costero del sur del país. Amenazas potenciales a poblaciones de esta especie corresponderín a modificación del hábitat.

\section{Nolana scaposa Femeyra}

DD

Publicación: Publ. Mus. Hist. Nat. «Javier Prado» Ser. B, Bot. 10: 5- 7, t. 3. 1955.

Colección tipo: R. Ferreyra 2538

Herbarios: GH; USM!.

Nombre común: D esconocido.

Registro departamental: AR.

Regiones Ecológicas: D ST; $20-250 \mathrm{~m}$.

SINANPE: Sin registro.

Herbarios penuanos: USM (holotipo+2). 
Observaciones: Planta anual, pubescente, conocida solamente de una localidad en el sur del país. La recolecta más reciente proviene de 1957. No se conoce el estatus de sus poblaciones. Tago-Nakazawa \& Dillon (1999) incluyeron esta especie en su estudio filogenético que parece relacionarla con otra endémica, $\mathrm{N}$ olana arenioola.

98. Nolana spathulata Ruiz \& Pav.

\section{NT}

Publicación: Fl. Peruv. 2: 7, t. 113a. 1799.

Colección tipo: J. Tafalla s.n.

Herbarios: FI, G, MA.

Nombre común: D esconocido.

Registro departamental: AR, IC, MO, TA.

Regiones Ecológicas: D ST; 50- $1000 \mathrm{~m}$.

SINANPE: Sin registro.

Herbarios penuanos: HAO (5), USM (14).

Observaciones: Esta especie anual se conoce de poblaciones naturalmente fragmentadas, a lo largo de la costa de Ica a Tacna. Mesa (1981) la incluyó como una subespecie de $\mathrm{N}$ olana humifusa, pero Macbride (1960) y Tago-Nakazawa \& Dillon (1999) la aceptan como especie. La mayoría de los registros provienen de años de «El Niño».

\section{Nolana thinophila I.M. Johnst.}

\section{VU, B lab(iii)}

Publicación: Contr. Gray Herb. 112: 56. 1936.

Colección tipo: F.W. Pennell 14280

Hembarios: GH, K, S, US.

Nombre común: D esconocido.

Registro departamental: AR, IC.

Regiones Ecológicas: D ST; 5- $500 \mathrm{~m}$.

SINAN PE: Sin registro.

Herbarios peruanos: HAO (2), MOL (2), USM (8).

Observaciones: Esta especie anual se conoce de siete localidades, del sur de Ica a Arequipa. O cupa diferentes condiciones ecológicas, desde ambientes influenciados por concentración alta de sales hasta pedregosos. Una de las poblaciones en los alrededores de Mejía fue recolectado cerca al mar; esta localidad podría corresponder a la Reserva Nacional Lagunas de Mejía, la que desafortunadamente recibe fuerte impacto por la expansión agrícola.

\section{Nolana tomentella F emeyra}

\section{EN, Bla}

Publicación: Publ. Mus. Hist. Nat. «Javier Prado» Ser. B, Bot. 10: 10-11, t. 7. 1955. Colección tipo: R. Ferreyra 8806

Herbarios: $\mathrm{GH}, \mathrm{K}$.

Nombre común: D esconocido.

Registro departamental: AR, IC.

Regiones Ecológicas: D ST; 200- $700 \mathrm{~m}$.

SINAN PE: Sin registro.

Herbarios penuanos: HAO (1), USM (1).

Observaciones: Esta especie perenne se conoce de dos localidades, naturalmente fragmentadas, separadas por cerca de $120 \mathrm{~km}$. La recolecta conocida más reciente proviene de 1986.

\section{Nolana tovaniana Femeyra}

$$
\text { EN, Bla }
$$

Publicación: Publ. Mus. Hist. Nat. «Javier Prado» Ser. B, Bot. 10: 14-15, t. 10. 1955.

Colección tipo: R. Ferreyra 8861

Hembarios: GH; MOL, USM.

Nombre común: D esconocido.

Registro departamental: AR.

Regiones Ecológicas: D ST; 300- $700 \mathrm{~m}$. SINANPE: Sin registro.

Herbarios peruanos: MOL (isotipo), USM (isotipo+5).

Observaciones: Esta especie perenne se conoce de cuatro localidades, naturalmente fragmentadas, ubicadas a lo largo de la costa de A requipa. Las recolectas más recientes provienen de 1959.

\section{Nolana urubambae Vargas}

\section{CR, Blab(iii)}

Publicación: Revista Univ. (Cuzco) 43(107): 154, t. 4. 1955.

Colección tipo: C. Vargas C. 7864

Hebarios: GH; USM!

Nombre común: Desconocido.

Registro departamental: CU.

Regiones Ecológicas: MA; $2860 \mathrm{~m}$.

SINANPE: Sin registro.

Herbarios peruanos: USM (isotipo).

Observaciones: Especie subarbustiva conocida sólo de una localidad, en la cuenca del río Urubamba y, al parecer, no ha vuelto a ser recolectada desde 1949. Mesa (1981) la incluyó en la sinonimia de otra endémica, Nolana humifusa, pero esa especie está limitada a la vertiente occidental. Ha sido reconocida por el INRENA como especie amenazada, concordando con la categońa que aquí se la aplica.

\section{Nolana volcanica Ferreyra}

\section{CR, Bla}

Publicación: Publ. Mus. Hist. Nat. «avier Prado», Ser. B, Bot. 12: 3- 4. 1960.

Colección tipo: D. Stafford 881

Herbarios: K; USM (fr)!.

Nombre común: Desconocido.

Registro departamental: AR.

Regiones Ecológicas: DST; $600 \mathrm{~m}$.

SINANPE: Sin registro.

Herbarios penuanos: USM (fragmento tipo).

Observaciones: Esta especie subarbustiva se conoce solamente de una localidad, en Arequipa. La recolecta más reciente proviene de 1986 durante un año de «El Niño». Mesa (1981) la incluyó en la sinonimia de $\mathrm{N}$ olana sedifolia subsp. confinis, pero este estatus taxonómico no fue aceptado por Tago-Nakazawa \& Dillon (1999).

\section{Nolana weberbaueri I.M. Johnst.}

\section{DD}

Publicación: Contr. Gray Herb. 112: 58. 1936.

Colección tipo: A. Weberbauer 5385

Hemarios: F, GH, US; USM!.

Nombre común: D esconocido.

Registro departamental: IC.

Regiones Ecológicas: MDE; 1000— 1200 m.

SINANPE: Sin registro.

Herbarios peruanos: USM (isotipo). 
Observaciones: Especie anual conocida aparentemente de una localidad, en Ica. Mesa (1981) la incluyó en la sinonimia de $\mathrm{N}$ olana laxa, una especie del Perú y Chile. No ha vuelto a ser recolectada desde 1910.

\section{Nolana weissiana Ferreyra}

$$
\text { EN, B1a }
$$

Publicación: Publ. Mus. Hist. Nat. «Javier Prado», Ser. B, Bot. 10: 9- 10, t. 6. 1955. Colección tipo: R. Ferreyra 7232

Herbarios: GH; USM!.

Nombre común: D esconocido.

Registro departamental: AR.

Regiones Ecológicas: D ST; 200-450 m.

SINAN PE: Sin registro.

Herbarios penuanos: USM (holotipo+5).

Observaciones: Esta especie subarbustiva se conoce solamente de dos localidades, en el sur del país. El área de presencia de esta especie se considera de $400 \mathrm{~km}^{2}$. Las colecciones cubren un periodo de cuatro décadas, entre 1946 y 1984, pero aparentemente no se han registrado colecciones adicionales más recientes.

\section{Nolana willeana Ferreyra}

\section{CR, Blab(iii)}

Publicación: Publ. Mus. Hist. Nat. «Javier Prado», Ser. B, Bot. 12: 1-2. 1960.

Colección tipo: M.E. Köie s.n.

Herbarios: ; USM!.

Nombre común: D esconocido.

Registro departamental: IC.

Regiones Ecológicas: D ST; $700 \mathrm{~m}$.

SINANPE: Sin registro.

Hemarios peruanos: USM (holotipo).

Observaciones: Esta especie perenne se conoce solamente de una localidad, con lomas y no ha vuelto a ser recolectada desde 1956. La localidad original, está ubicada en una zona sujeta a modificaciones ambientales por procesos naturales e intervención humana.

\section{Physalis quillabambensis D. Medina}

\section{DD}

Publicación: Amaldoa 5(2): 211, f. 1. 1998.

Colección tipo: D. Medina 314

Herbarios: ; HAO !, HUT!

Nombre común: D esconocido.

Registro departamental: AY, CU, JU.

Regiones Ecológicas: BMHP; 870 — $1230 \mathrm{~m}$.

SINAN PE: Sin registro.

Herbarios peruanos: HAO (isotipo), HUT

(holotipo+3).

Observaciones: Esta especie herbácea se conoce principalmente de localidades en el sur del país; sin embargo, la descripción original incluye poblaciones disyuntas en Cajamarca.

\section{Salpichroa dependens (Hook.) Miers}

\section{VU, Bla}

Publicación: London J. Bot. 4: 325. 1845.

Colección tipo: A. Mathews 829

Herbarios: $\mathrm{K}$.

Nombre común: D esconocido.

Registro departamental: AY, HV, JU.

Regiones Ecológicas: MA, PSH, BPM; 3400-3780 m.

SINANPE: Sin registro.

Herbarios peruanos: MOL (1), USM (5).
Observaciones: Esta especie arbustiva, escandente, se conoce de las partes altas de las cuencas del Mantaro y del Huallaga. Citada por Macbride (1962) erróneamente para Lima, sobre la base de un ejemplar de Weberbauer recolectado en la Provincia de Huancayo en Junín. Se conoce de por lo menos siete localidades y probablemente existan otras poblaciones en fragmentos de bosque de los tributarios de los ríos antes mencionados.

\section{Salpichroa didierana Jaubert}

$$
\text { EN, Blab(iii) }
$$

Publicación: Bull. Soc. Bot. France 8: 117. 1861.

Colección tipo: E. Grandidier \& A. Grandidier s.n.

Herbarios: P.

Nombre común: Jacapaillo.

Registro departamental: CU.

Regiones Ecológicas: $\mathrm{BPM}, \mathrm{BMHM}$; 3110- $4300 \mathrm{~m}$.

SINANPE: PNM

Herbarios peruanos: USM (2).

Observaciones: Este arbusto trepador se conoce solamente de cuatro localidades, en el lado oriental de Cusco, al parecer, localmente frecuente, pero su hábitat es propenso a modificación por incendios intencionales y extracción de leña.

\section{Salpichroa gayi Benoist}

\section{DD}

Publicación: Bull. Soc. Bot. France 85: 54. 1938.

Colección tipo: C. Gay 2308

Herbarios: P.

Nombre común: Pepino silvestre; pirespires, rocotitos.

Registro departamental: CU.

Regiones Ecológicas: MA, PSH; 3550$3600 \mathrm{~m}$.

SINANPE: Sin registro.

Herbarios penuanos: USM (2).

Observaciones: Especie arbustiva, escandente, conocida de dos poblaciones en las cuencas de los ríos Vilcanota y Urubamba. Poco se sabe del estado de las poblaciones. Sus frutos son comestibles.

\section{Saracha spinosa (Dammer) D’Arcy \& D.N. Sm.}

\section{VU, Bla}

Publicación: Ann. Missouri Bot. Gard. 74(3): 674-675. 1987.

Colección tipo: A. Weberbauer 2907

Herbarios: B; MOL!

Nombre común: Desconocido.

Registro departamental: AN, AP, AY, HV, LI.

Regiones Ecológicas: MA, PSH; 3500$4000 \mathrm{~m}$.

SINAN PE: Sin registro.

Herbarios peruanos: MOL (isotipo), USM (6).

Observaciones: Este arbusto, espinoso, fue recolectado inicialmente de la vertiente oriental de la Cordillera Blanca. Hoy se conoce de más de seis poblaciones provenientes de ambientes semixéricos, en las cuencas del Mantaro, Apurímac y Rímac. 


\section{Solanum acroscopicum 0 choa}

\section{NE}

Publicación: Agronomía (Lima) 18(74): 130, f. 3-4. 1953.

Colección tipo: C. O choa 2043

Herbarios: GH, US; MOL!.

Nombre común: D esconocido.

Registro departamental: AR, AY, MO, TA Regiones Ecológicas: MA, PSH; 3000$3900 \mathrm{~m}$.

SINANPE: Sin registro.

Herbarios peruanos: MOL (isotipo+2).

Observaciones: Especie diploide perteneciente a Solanum Sección Petota. Brako \& Zarucchi (1993) la consideraron como no reconfirmada. Sin embargo, se conoce de más de 15 localidades principalmente en las partes altas de la vertiente occidental de Ayacucho a Tacna.

\section{Solanum amayanum 0 choa}

\author{
NE \\ Publicación: Amer. Potato J. 66: 1-4. \\ 1989. \\ Colección tipo: C. O choa 4299 \\ Herbarios: F, GH, US; MOL, USM. \\ Nombre común: D esconocido. \\ Registro departamental: $\mathrm{HV}$. \\ Regiones Ecológicas: PSH; 3000 - 3900 m. \\ SINANPE: Sin registro. \\ Herbarios peruanos: MOL (isotipo+1), \\ USM (2).
}

Observaciones: Esta hierba, diploide, pertenece aSolanum Sección Petota. Su distribución está limitada a la cuenca alta del río Mantaro. Brako \& Zarucchi (1993) la consideraron una especie no reconfirmada y erróneamente no fue señalada como endémica.

\section{Solanum amblophyllum H ook.}

\section{VU, Bla}

Publicación: Bot. Misc. 2: 231. 1831 Colección tipo: C. Wilkes, Exped. Expl. US. s.n.

Hembarios: K, US.

Nombre común: D esconocido.

Registro departamental: LI.

Regiones Ecológicas: MA; 2900-3500 m.

SINANPE: Sin registro.

Herbarios penuanos: MOL (1), USM (13).

Observaciones: Esta especie arbustiva se conoce de varias localidades, en las cuencas medias de los ríos Chillón y Rímac. Localmente frecuente, pero el área de presencia es muy reducido. La localidad original, en la cuenca del Chillón, aún mantiene poblaciones de esta especie.

\section{Solanum ambosinum 0choa}

\section{LC}

Publicación: Biota, Lima 1: 71954.

Colección tipo: C. Ochoa 1040

Herbarios:

Nombre común: Auquillo papa; punum papa

Registro departamental: AN, HU, PA.

Regiones Ecológicas: MA; 2200-3600 m.

SINAN PE: Sin registro.

Herbarios penuanos: MOL, USM?
Observaciones: Esta especie diploide pertenece a Solanum Sección Petota. Se conoce de numerosas localidades, ubicadas tanto en la vertiente occidental de Ancash, cuencas del Tablachaca, Huarmey y Fortaleza, como en la oriental, en las cuencas del Marañón y Huallaga.

\section{Solanum amnicola S. Knapp}

$$
\text { VU, Bla }
$$

Publicación: Brittonia 38(3): 295-298, f. 15-16. 1986 .

Colección tipo: S. Knapp \& J. Mallet 6651

Herbarios: BH, NY, US; USM!.

Nombre común: D esconocido.

Registro departamental: AM, CU, LO, PA, PU.

Regiones Ecológicas: BHA; 350-1100 m. SINANPE: PNBS, PNM

Herbarios penuanos: USM (isotipo).

Observaciones: Esta especie arbustiva se conoce de seis localidades, en las cuencas del Mayo, Alto Madre de Dios, Alto Inambari, Palcazú, entre otros. Probablemente esté representada en la flora de Bolivia.

\section{Solanum anamatophilum 0 choa}

\section{EN, Bla}

Publicación: Anales Ci. Univ. Nac. Agrar. 2(4): 391-395. 1964.

Colección tipo: C. O choa 2490

Hembanios: LE, MO; USM!.

Nombre común: Papa de zorro.

Registro departamental: AN.

Regiones Ecológicas: MA; 2750- 2820 m. SINAN PE: Sin registro.

Herbarios peruanos: MOL(1), USM (isotipo+1).

Observaciones: Esta especie herbácea, diploide, de la Sección Petota, se conoce de ambientes xéricos, en la Provincia de Bolognesi, en un área menor a los $2000 \mathrm{~km}^{2}$.

\section{Solanum ancophilum (Corr.) 0 choa}

\section{DD}

Publicación: Phytologia 54(5): 392. 1983. Colección tipo: D.S. Correll \& E.E. Smith P-957

Herbanios: K, LL, MO, NY, S, US; USM.

Nombre común: D esconocido.

Registro departamental: AN, LL.

Regiones Ecológicas: MA, PSH; 2600$4280 \mathrm{~m}$.

SINANPE: PNH

Henbarios peruanos: HUT (2), MOL (1), USM (isotipo citado+2).

Observaciones: Esta hierba, diploide, pertenece a la Sección Petota. Se conoce de la cuenca del Santa y Pativilca; al parecer, forma colonias grandes en roquedales. Se desconoce el estado de sus poblaciones. 


\section{Solanum anconipae 0 choa}

\section{DD}

Publicación: Papas Sudamer. Peru 544545, 547, f. 231-235. 1999.

Colección tipo: C. O choa 13662

Herbarios: MOL!

Nombre común: D esconocido.

Registro departamental: AP.

Regiones Ecológicas: MA; 2700-3000 m.

SINAN PE: Sin registro.

Herbarios penuanos: MOL (isotipo).

Observaciones: Hierba diploide que pertenece a la Sección Petota. Conocida delas cuencas de los ríos Mataráy Vilcabamba en Apurímac. La localidad original está ubicada en un matorral ribereño de un tributario del Vilcabamba. Se desconoce el estado de sus poblaciones.

\section{Solanum andersonii 0 choa}

\section{NE}

Publicación: Phytologia 46: 225. 1980.

Colección tipo: C. O choa 13026

Herbarios: US; MOL!.

Nombre común: D esconocido.

Registro departamental: IC.

Regiones Ecológicas: DST; $700 \mathrm{~m}$.

SINANPE: Sin registro.

Herbarios peruanos: MOL (isotipo).

Observaciones: Esta especie está bajo revisión taxonómica.

\section{Solanum angustialatum Bitter}

\section{CR, Bla}

Publicación: Repert. Spec. Nov. Regni Veg. 11: 471. 1912.

Colección tipo: R. Spruce 4849

Herbarios: W.

Nombre común: D esconocido.

Registro departamental: SM.

Regiones Ecológicas: BMHP; 700—1200 m.

SINAN PE: Sin registro.

Herbarios peruanos: USM (1).

Observaciones: Esta especie subarbustiva pertenece a la Sección Pteroidea. Knapp \& Helgason (1997) señalaron que se conoce solamente de los alrededores de Tarapoto. Los ejemplares citados por Macbride (1962) corresponden a otra especie. Indicaron, también, que probablemente se encuentre a lo largo de la cadena montañosa que incluye a Cerro La Escalera, hoy parte del Parque Nacional Cordillera Azul.

\section{Solanum arcanum Peralta}

\section{NT}

Publicación: Syst. Bot. 30: 424, f. 1. 2005. Colección tipo: P.C. Hutchison \& J.K. Wright 5449

Hemarios: F, K, M, MICH, MO, NY, UC, US; USM.

Nombre común: Desconocido.

Registro departamental: AM, AN, CA, LL, PI.

Regiones Ecológicas: DCT, MDE, MA; $100-2500 \mathrm{~m}$

SINANPE: Sin registro.

Herbarios penuanos: USM (holotipo+12),

HUT (5).
Observaciones: Esta especie herbácea forma parte de un complejo llamado antes L yoopersicon peruvianum. Solanum arcanum habita ambientes semixéricos en la costa, vertiente del Pacífico y laderas de las cuencas del Marañón, Utcubambay Huancabamba. La población original se conoce de Cerros Calla Calla. Sus poblaciones en los ambientes de lomas, podrían estar amenazadas por modificación de hábitat.

\section{Solanum aniduphilum 0choa}

\section{DD}

Publicación: Bol. Soc. Argent. Bot. 14(4): 330, 332, 334, t I-II. 1972.

Colección tipo: C. O choa 2637

Herbarios: USM!

Nombre común: Amaa papa.

Registro departamental: $\mathrm{HU}$.

Regiones Ecológicas: MA, PSH; 3340$3720 \mathrm{~m}$.

SINAN PE: Sin registro.

Herbarios peruanos: USM (isotipo).

Observaciones: Esta especie herbácea, diploide, pertenece a la Solanum Sección Petota y se conoce solamente de tres localidades todas ubicadas en la Provincia de Huamalíes, en la cuenca del Maranón. Se desconoce el estado de sus poblaciones.

\section{Solanum augusti 0 choa}

\section{NE}

Publicación: Bol. Soc. Peruana Bot. 7(12): 12-15. 1974.

Colección tipo: C. Ochoa 3317

Herbarios: ; USM!.

Nombre común: Desconocido.

Registro departamental: AN.

Regiones Ecológicas: MA, PSH; 3000$3800 \mathrm{~m}$.

SINANPE: Sin registro.

Herbarios peruanos: MOL (2), USM (isotipo).

Observaciones: Esta hierba diploide pertenece a la Sección Petota. Se conoce de tres localidades en la vertiente occidental de Ancash, de las cuencas de los ríos Huarmey y Culebras. Parece hibridar con otras especies en la sección (O choa, 1999).

\section{Solanum ayacuchense 0 choa}

$$
\text { EN, Blab(iii) }
$$

Publicación: Agronomía (Lima) 26: 312, f. 312, 313. 1959.

Colección tipo: C. O choa 2150

Herbarios:

Nombre común: Desconocido.

Registro departamental: AY.

Regiones Ecológicas: MA; 3000-3200

m.

SINANPE: Sin registro.

Herbarios peruanos: Ninguno.

Observaciones: Esta especie diploide pertenece a Solanum Sección Petota. Se conoce del noreste de Ayacucho. O choa (1999) señala que es rara en su hábitat natural, el que está integramente destruido por acción humana. 


\section{Solanum aymaraesense 0 choa}

\section{DD}

Publicación: Phytologia 64(1): 36-37. 1987.

Colección tipo: C. O choa 4150

Herbarios: US.

Nombre común: D esconocido.

Registro departamental: AP.

Regiones Ecológicas: MA; 2400-2600 m.

SINANPE: Sin registro.

Hemarios peruanos: Ninguno.

Observaciones: Esta especie diploide pertenece a Solanum Sección Petota. Se conoce solamente de una localidad, en la cuenca del Chalhuanca. Se desconoce el estado de sus poblaciones.

\section{Solanum billhookeri Ochoa}

\section{CR, B lab(iii)}

Publicación: Am. Potato J. 65: 737-740. 1988.

Colección tipo: C. O choa 4295

Herbarios: F, GH, US; USM!.

Nombre común: D esconocido.

Registro departamental: HV.

Regiones Ecológicas: MA; 2900-3200 m.

SINANPE: Sin registro.

Herbarios peruanos: USM (isotipo).

Observaciones: Esta especie diploide se conoce solamente de una localidad, la que erróneamente fue citada en Brako \& Zarucchi (1993) como Huánuco. No ha vuelto a ser recolectada desde 1985; según O choa (1999), está amenazada por el pastoreo intensivo.

\section{Solanum buesii Vargas}

\section{NT}

Publicación: Revista Argent. Agron. 10(4): 396- 397. 1943.

Colección tipo: C. Vargas C. 2877

Herbarios: LL; $\underline{\text { CUZ. }}$

Nombre común: D esconocido.

Registro departamental: CU.

Regiones Ecológicas: $\mathrm{BPM}, \mathrm{BMHM}$; 2400- $3650 \mathrm{~m}$.

SINAN PE: SHMP, PNM

Herbarios penuanos: MOL (5), USM (2).

Observaciones: Esta especie pertenece a Solanum Sección Petota. Se conoce de unas siete poblaciones, ubicadas en los bosques pluviales montanos de Cusco, cuencas del Urubamba y Alto Madre de Dios.

\section{Solanum bukasovii Juz.}

\section{LC}

Publicación: Bull. Acad. Sci. U.S.S.R. 2: 3031937.

Colección tipo: S.V. Juzepczuk 10605

Herbarios: LE.

Nombre común: Arak papa; atokk papa; jupay papa; pishi akshu.

Registro departamental: AN, AP, AR, AY, CU, HU, HV, JU, LI, MO, PA, PU.

Regiones Ecológicas: MA, PSH; 2000$4000 \mathrm{~m}$.

SINANPE: Sin registro.

Herbarios penuanos: MOL (3), USM (2)
Observaciones: Esta especie pertenece a Solanum Sección Petota. Probablemente sea la de mayor importancia en el origen de la papa cultivada, así como por su potencial para mejoramiento genético (O choa, 1999). Esta especie tiene un amplio rango de distribución altitudinal, pero se encuentra preferentemente en los pajonales andinos. Probablemente se presente en la flora boliviana.

\section{Solanum burkartii Ochoa}

\section{DD}

Publicación: Biota (Lima) 11(87): 9798. 1977.

Colección tipo: C. O choa 11060

Herbarios:

Nombre común: Papa del puro macho.

Registro departamental: AM.

Regiones Ecológicas: BMHM; 2800$3000 \mathrm{~m}$.

SINAN PE: Sin registro.

Herbarios peruanos: Ninguno.

Observaciones: Hierba diploide perteneciente a Solanum Sección Petota, conocida solamente de una localidad en el occidente de Amazonas. Se desconoce el estado de sus poblaciones.

\section{Solanum cajamarquense 0 choa}

\section{DD}

Publicación: Agronomía (Lima) 26(4): 314-316. 1959.

Colección tipo: C. O choa 1490

Henbarios: F, GH; MOL, USM.

Nombre común: D esconocido.

Registro departamental: CA.

Regiones Ecológicas: MA; 2200-3000 $\mathrm{m}$.

SINANPE: Sin registro.

Hembarios penuanos: MOL (isotipo), USM (isotipo citado+10).

Observaciones: Esta especie pertenece a Solanum Sección Petota. Se conoce de siete localidades, en tres provincias cajamarquinas, tanto en vertiente occidentales como valles interandinos. Escasa en las localidades conocidas. Se desconoce el estado de sus poblaciones.

\section{Solanum cantense 0 choa}

\section{DD}

Publicación: Agronomía (Lima) 26(3): 217-218. 1959.

Colección tipo: C. O choa 1154

Herbarios: LE.

Nombre común: Papa de gentil, papa del abuelo, papa de alma, papa cimarrón.

Registro departamental: AN, LI.

Regiones Ecológicas: MA; 2400-3300 $\mathrm{m}$.

SINAN PE: Sin registro.

Hemarios peruanos: MOL(2), USM (5).

Observaciones: Esta especie pertenece a Solanum Sección Petota y se conoce de varias localidades, en lavertiente occidental, incluyendo el Bosque de Zárate, en la cuenca del Rímac. Se desconoce el estado de sus poblaciones. 


\section{Solanum catilliflorum G.J. Anderson, Martine, Prohens \& Nuez}

$$
\text { EN, B1a }
$$

Publicación: Novon 16(2): 164-165, f. 1E-H. 2006

Colección tipo: C.T. Martine 949

Herbarios: CONN, MO, NY, VAL; MOL.

Nombre común: Pipino.

Registro departamental: AP.

Regiones Ecológicas: MA; $2100 \mathrm{~m}$.

SINAN PE: Sin registro.

Herbarios peruanos: MOL (isotipo citado).

Observaciones: Liana conocida solamente de una localidad, en la cuenca del Pachachaca. Los frutos de esta especie son valorados como alimento, además está relacionado con el «pepino» (Anderson et al. 2006). Esta especie se conoce de matorrales muy deteriorados.

\section{Solanum chamaepolybotryon Bitter}

$$
\text { EN, Bla }
$$

Publicación: Repert. Spec. Nov. Regni Veg. 11: 471. 1912.

Colección tipo: R. Spruce 4432

Herbarios: $\mathrm{K}, \mathrm{W}$.

Nombre común: D esconocido.

Registro departamental: SM.

Regiones Ecológicas: BMHP; 950- 1400

m.

SINANPE: Sin registro.

Herbarios peruanos: USM (1).

Observaciones: Esta especie pertenece a Solanum Sección Pteroideø. Se conoce solamente de tres localidades, en una de las cuales forma aparentemente clones grandes (Knapp \& Helgason, 1997).

\section{Solanum chancayense 0 choa}

\section{DD}

Publicación: Agronomía (Lima) 26(4): 316-318. 1959.

Colección tipo: C. Ochoa 1804

Herbarios:

Nombre común: Papa de loma.

Registro departamental: LI, LL.

Regiones Ecológicas: DST; $150-550 \mathrm{~m}$.

SINANPE: RNL

Hembarios peruanos: USM (6).

Observaciones: Especie diploide perteneciente a Solanum Sección Petota. Se conoce de poblaciones naturalmente fragmentadas. Se desconoce el estado de sus poblaciones.

\section{Solanum chillonanum 0choa}

\section{DD}

Publicación: Phytologia 67(3): 235. 1989. Colección tipo: C. Ochoa 4101

Herbarios: US.

Nombre común: Desconocido.

Registro departamental: AP.

Regiones Ecológicas: PSH; 4000-4100

$\mathrm{m}$.

SINAN PE: Sin registro.

Herbarios penuanos: MOL (1)?, USM (1).
Observaciones: Especie perteneciente a Solanum Sección Petota. Tiene afinidad con Solanum bukasovii (O choa, 1999). Se conoce solamente de dos localidades y se desconoce el estado de sus poblaciones.

\section{Solanum chiquidenum 0choa}

$$
\text { EN, Bla }
$$

Publicación: Biota 1(1): 5, f. 1-2. 1954. Colección tipo: C. Ochoa 1505

Hemanios: ; MOL, USM!

Nombre común: Papa del zorro.

Registro departamental: AN, CA, LL. Regiones Ecológicas: MA, PAR; 1500$3800 \mathrm{~m}$.

SINANPE: Sin registro.

Herbarios peruanos: CPUN (1), MO L (isotipo citado), USM (isotipo+25).

Observaciones: Esta especie herbácea, de la Sección Petota, se conoce de varias poblaciones aisladas, en un área aproximada a los $7000 \mathrm{~km}^{2}$. Estas poblaciones están constituidas por pocos individuos por deterioro del hábitat.

\section{Solanum clivorum S. Knapp}

\section{VU, Bla}

Publicación: Novon 2(4): 341-343, f. 1, 5. 1992.

Colección tipo: R. Ferreyra 3059

Herbarios: IBE, MO, US; USM.

Nombre común: Shirac.

Registro departamental: CA, LL.

Regiones Ecológicas: MA, PAR; 2500$3200 \mathrm{~m}$.

SINANPE: Sin registro.

Herbarios penuanos: HAO (1), HUT (2), USM (holotipo citado).

Observaciones: Esta especie arbustiva se conoce de las cuencas del Chotano y del Cajamarca, donde habita fragmentos de matorrales. Amenazas a sus poblaciones están asociadas aincendios intencionales.

\section{Solanum coelestispetalum Vargas}

\section{NE}

Publicación: Papas Sudper. 2: 59, f. 15. 1954.

Colección tipo: C. Vargas C. 5990

Herbarios: TEX-LL; $\underline{\text { CUZ. }}$.

Nombre común: D esconocido.

Registro departamental: AP, CU.

Regiones Ecológicas: MA, BPM, BMHM; 2250-3700 m.

SINANPE: SHMP

Herbarios peruanos: CUZ (tipo citado), USM (16).

Observaciones: Especie perteneciente a la Sección Petota, conocida de ocho localidades en el centro del país. Hibridiza con otras especies de Solanum Sección Petota (Ochoa, 1999). 


\section{Solanum contumazaense 0 choa}

\section{DD}

Publicación: Anales Ci. Univ. Nac. Agrar. 2(2): 148-151. 1964.

Colección tipo: C. O choa 2485

Herbarios: GH, LE, MO, US.

Nombre común: D esconocido.

Registro departamental: CA.

Regiones Ecológicas: MA; 2500-2840 m.

SINANPE: Sin registro.

Hemarios penuanos: HAO (1), HUT(7).

Observaciones: Especie perteneciente a Solanum Sección Petota. Conocida delas vertientes occidentales de Cajamarca. Se desconoce el estado de sus poblaciones.

\section{Solanum dolichocremastrum Bitter}

\section{NE}

Publicación: Repert. Spec. Nov. Regni Veg. 12: 3-4. 1913.

Colección tipo: J. D ombey s.n.

Herbarios: P.

Nombre común: Jupaya papa; papa de gentil. Registro departamental: AN, HU, LL. Regiones Ecológicas: PSH, PAR; 3600$4280 \mathrm{~m}$.

SINANPE: PNH

Herbarios penuanos: CPUN (1), HAO (1), USM (1).

Observaciones: Esta especie pertenece a Solanum Sección Petota. Se conoce de las serranías de La Libertad, Ancash y Huánuco (O choa, 1999). Puede hibridar con otras especies en la Sección Petota (O choa, 1999).

\section{Solanum fulgens (J.F. Macbr.) K.E. Roe}

\section{EN, Bla}

Publicación: Brittonia 24(3): 275-276. 1972.

Colección tipo: E.P. Killip \& A.C. Smith 25969

Herbarios: F, NY, US.

Nombre común: D esconocido.

Registro departamental: JU.

Regiones Ecológicas: BMHP; $1100 \mathrm{~m}$.

SINANPE: Sin registro.

Herbarios peruanos: USM (1).

Observaciones: Esta especie pertenece a Solanum Sección Brevantherum (Roe, 1972). Se conoce solamente de dos localidades, en el valle del Chanchamayo, cuenca del río Tulumayo.

\section{Solanum gracilifrons Bitter}

\section{DD}

Publicación: Bot. Jahrb. Syst. 54(Beibl. 119): 6- 7. 1916.

Colección tipo: A. Weberbauer 6472

Herbarios: B (d); MOL!

Nombre común: D esconocido.

Registro departamental: HV.

Regiones Ecológicas: MA, BS; 1600-

$2000 \mathrm{~m}$.

SINAN PE: Sin registro.

Herbarios peruanos: MOL (lectotipo), USM (1).
Observaciones: Esta especie diploide pertenece a Solanum Sección Petota Serie Tuberosa y se conoce solamente de una localidad, en la cuenca del río Mantaro. O choa (1999) intentó recolectar material adicional en 1996, pero sin éxito. Se desconoce el estado de sus poblaciones.

\section{Solanum guzmanguense Whalen \& Sagást.}

$$
\text { EN, B1a }
$$

Publicación: Brittonia 38(1): 9, f. 1. 1986. Colección tipo: A. Sagástegui A. et al. 9714 Hemanios: BH; HUT!

Nombre común: D esconocido. Registro departamental: CA. Regiones Ecológicas: MDE; 1700- 2200 m.

SINANPE: Sin registro.

Herbarios peruanos: HAO (5), HUT (holotipo).

Observaciones: Esta especie diploide pertenece a Solanum Sección Petota Serie Simplicissima. Brako \& Zarucchi (1993) la listaron como sin confirmar. Sin embargo, se conoce de tres localidades en la vertiente occidental de Cajamarca, entre las cuencas del Magdalena y Alto Chicama, donde ha sido recolectada los últimos 10 años (Ochoa, 1999).

\section{Solanum habrocaulon S. Knapp}

$$
\text { CR, Bla }
$$

Publicación: Novon 6: 31. 1996.

Colección tipo: S. Knapp et al. 7507

Hemarios: MO, NY; USM.

Nombre común: Desconocido.

Registro departamental: AM.

Regiones Ecológicas: BMHM; 2150$2200 \mathrm{~m}$.

SINANPE: Sin registro.

Henbarios peruanos: USM (holotipo).

Observaciones: Esta especie pertenece a Solanum Sección $\mathrm{G}$ eminata (Knapp, 2002). Se conoce de una localidad, en la cuenca del Utcubamba, la cual incluye áreas de bosque húmedo sometido a intensa deforestación.

\section{Solanum hastiforme Correll}

NE

Publicación: Wrightia 2: 187-188. 1961. Colección tipo: D.S. Correll \& E.E. Smith P930

Hemanios: TEX-LL, US.

Nombre común: Candullpa (fruto).

Registro departamental: AN, LL.

Regiones Ecológicas: MA, PAR, BPM; 2800-3900 m.

SINAN PE: PNH

Hemarios peruanos: CPUN (1), MOL?, USM (3).

Observaciones: Especie diploide que pertenece a Solanum Sección Petota. Se conoce de ambientes de jalca en el norte del país. O choa (1999) tuvo éxito con algunos de los cruzamientos entre esta especie y otras en la Sección Petota. 
147. Solanum hispidum Pers. var. cerrateae J.F. Macbr.

\section{NE}

Publicación: Field Mus. Nat. Hist., Bot. Ser. 13(5B/ 1): 252. 1962.

Colección tipo: F.W. Pennell 14066

Herbarios: US.

Nombre común: Desconocido.

Registro departamental: AP, CU.

Regiones Ecológicas: BMHM; 2000$2300 \mathrm{~m}$.

SINANPE: PNM, SNA

Herbarios peruanos: USM (1).

Observaciones: Este taxón pertenece a Solanum Sección Torva y se conoce solamente de dos localidades en el suroriente del país. Se encuentra bajo estudio taxonómico.

148. Solanum hispidum Pers. var. ferneyrae J.F. Macbr.

\section{NE}

Publicación: Field Mus. Nat. Hist., Bot. Ser. 13(5B/1): 252. 1962.

Colección tipo: G. Klug 3203

Herbarios: US.

Nombre común: D esconocido.

Registro departamental: LO.

Regiones Ecológicas: BMHP; 600- 1200

m.

SINAN PE: Sin registro.

Herbarios peruanos: Ninguno.

Observaciones: Este taxón pertenece a Solanum Sección Torva y se encuentra bajo revisión taxonómica.

\section{Solanum huancabambense 0 choa}

\section{DD}

Publicación: Agronomía (Lima) 26: 109 1959.

Colección tipo: C. O choa 2023

Henbarios: LE, P.

Nombre común: D esconocido.

Registro departamental: LA, PI.

Regiones Ecológicas: MDE, MA; 1800$2900 \mathrm{~m}$.

SINANPE: Sin registro.

Herbarios penuanos: MOL (2).

Observaciones: Especie diploide que pertenece a Solanum Sección Petota. Se conoce de varias localidades, en la vertiente occidental y del valle del Huancabamba en Piura. Se desconoce el estado de sus poblaciones.

\section{Solanum huancavelicae 0choa}

\section{DD}

Publicación: Papas Sudamericanas, Peru 693. 1999.

Colección tipo: C. O choa \& A. Salas 16272

Herbarios: ; MOL.

Nombre común: Atokk papa.

Registro departamental: HV.

Regiones Ecológicas: MA; $3300 \mathrm{~m}$.

SINAN PE: Sin registro.

Herbarios peruanos: MOL (isotipo).
Observaciones: Especie diploide que pertenece a Solanum Sección Petota. Se conoce solamente de una localidad, en la cuenca del Mantaro, donde es escasa. Se desconoce el grado de amenaza de sus poblaciones.

\section{Solanum huarochiniense 0choa}

\section{DD}

Publicación: Solanum Tubiferos Silvestres del Peru 215-217 1962.

Colección tipo: C. O choa 2308

Herbarios: US; MOL, USM.

Nombre común: Añas papa; papa ñame.

Registro departamental: AN, LI.

Regiones Ecológicas: PSH, AA; 3500$4400 \mathrm{~m}$.

SINAN PE: PNH

Herbarios peruanos: MOL (isotipo), USM (3).

Observaciones: Esta especie pertenece a Solanum Sección Petota. Se conoce de numerosas localidades, ubicadas principalmente en la parte altoandina de la cordillera occidental de Ancash y Lima. Se desconoce el grado de amenaza de sus poblaciones.

\section{Solanum huaylasense Peralta}

$$
\text { VU, Blab(iii) }
$$

Publicación: Syst. Bot. 30: 429, f. 3. 2005.

Colección tipo: E.E. Smith \& J. Blas 4889

Herbarios: F, US; USM.

Nombre común: Tomatillo.

Registro departamental: AN.

Regiones Ecológicas: MA; 1700-3000

$\mathrm{m}$.

SINANPE: Sin registro.

Herbarios peruanos: AMAZ (1), USM

(holotipo+3).

Observaciones: Esta hierba postrada, forma parte del complejo de L yopersion peruvianum. Habita ambientes semixéricos, en la cuenca del Santa. Recolectada de por lo menos cinco localidades, en el Callejón de Huaylas. Este valle está densamente poblado y los matorrales, de los que se conoce, son quemados frecuentemente. No se sabe con certeza el impacto de esta práctica a esta especie. La localidad original está ubicada en una ladera que recibe protección por parte del estado peruano, ya que ahí se encuentra la Cueva Guitarrero.

\section{Solanum humectophilum 0 choa}

\section{DD}

Publicación: Darwiniana 15(3-4): 550— 553. 1969.

Colección tipo: C. Ochoa 2668

Herbarios: GH, US; MOL.

Nombre común: Papa del macho, papa del gentil.

Registro departamental: AM.

Regiones Ecológicas: BMHM; 2800$3200 \mathrm{~m}$

SINANPE: Sin registro.

Herbarios peruanos: MOL (isotipo citado +2).

Observaciones: Esta especie diploide pertenece a Solanum Sección Petota. Se conoce delos alrededores de Leimebamba, siempre asociada a matorralesy fragmentos de bosque húmedo montano. Se desconoce el grado de amenaza de sus poblaciones. 
154. Solanum hutchisonii (J.F. Macbr.) Bohs

$$
\text { VU, Bla }
$$

Publicación: Syst. Bot. Monogr. 61: 55. 2001. Colección tipo: P.C. Hutchison 1490

Henbarios: F, G, K, NY, US.

Nombre común: D esconocido.

Registro departamental: AM, CA.

Regiones Ecológicas: BS; 350-1500 m.

SINAN PE: ZRCC

Herbarios penuanos: CPUN (1), HUT (1).

Observaciones: Esta especie arbustiva, de hojas carnosas, pertenece a Solanum Sección Cyphomandropsis (Bohs, 2001). Se conoce de varias poblaciones, en ambientes semixéricos, en las cuencas de los ríos Chinchipe, Marañón, Chotano, Tabaconas y Utcubamba.

\section{Solanum hypacrarthrum Bitter}

$$
\text { VU, Bla }
$$

Publicación: Repert. Spec. Nov. Regni Veg. 11: 367. 1912.

Colección tipo: A. Mathews $772 \mathrm{pp}$

Herbarios: CGE, E, G, K, L, OXF.

Nombre común: D esconocido.

Registro departamental: AN, LI.

Regiones Ecológicas: MDE, MA; $1000-$

$3800 \mathrm{~m}$.

SINAN PE: Sin registro.

Herbarios penuanos: USM (11).

Observaciones: Esta especie diploide pertenece a Solanum Sección Petota. El ejemplar tipo fue recolectado en 1832, en la cuenca del Chillón. Se conoce solamente de las vertientes occidentales, en el centro del país, incluyendo el Bosque de Zárate, en la cuenca del Rímac.

\section{Solanum immite Dunal}

\section{NE}

Publicación: Prodr. 13(1): 32. 1852. Colección tipo: H. Ruiz \& J. Pavón 8/90 pp Herbarios: G, MA.

Nombre común: Desconocido.

Registro departamental: AN, LL, LI. Regiones Ecológicas: DST, MDE; $80-$ $2500 \mathrm{~m}$.

SINANPE: RNL

Herbarios penuanos: CPUN (1), HUT (2), MOL (4), USM (3).

Observaciones: Especie pertenece a Solanum Sección Petota. Se conoce de varias localidades a lo largo de la costa y vertiente occidental de La Libertad a Lima. O choa (1999) indica que esta especie es compatible en cruzamientos con otras especies dela Sección.

\section{Solanum incahuasinum 0 choa}

\section{DD}

Publicación: Kurtziana 12-13: 183185. 1979.

Colección tipo: C. O choa 3595

Henbarios: ; MOL.

Nombre común: D esconocido.

Registro departamental: LA.

Regiones Ecológicas: MA; 2500- 2875 m.

SINANPE: Sin registro.

Herbarios peruanos: MOL (isotipo citado).
Observaciones: Esta especie diploide se conoce de dos localidades en Lambayeque. Pertenece a Solanum Sección Petota y parece formar un complejo, con otras dos especies endémicas, Solanum chancayense y S. mochiquense. Se desconoce el grado de amenaza.

\section{Solanum incasicum 0 choa}

\author{
NE \\ Publicación: Phytologia 48(3): 229-232. \\ 1981. \\ Colección tipo: C. O choa 4001 \\ Henbarios: LE. \\ Nombre común: D esconocido. \\ Registro departamental: CU. \\ Regiones Ecológicas: PSH, BPM; 3800- \\ $3900 \mathrm{~m}$. \\ SINANPE: Sin registro. \\ Herbanios penuanos: USM (1).
}

Observaciones: Esta especie pertenece a Solanum Sección Petota y se conoce solamente de dos localidades en la cuenca del río Urubamba. O choa (1999) logró cruzamientos exitosos con Solanum bukasovii, otra endémica en la Sección que incluye a las papas cultivadas.

\section{Solanum ingaefolium 0 choa}

\section{DD}

Publicación: Agronomía (Lima) 26(4): 319-322. 1959.

Colección tipo: C. O choa 1765

Herbarios: LE, P, US.

Nombre común: Papa de monte.

Registro departamental: PI.

Regiones Ecológicas: MA; 2400-3200 m.

SINAN PE: Sin registro.

Herbarios peruanos: MOL (2).

Observaciones: Esta especie pertenece a la Sección Petota y se conoce de unas cuatro poblaciones, cerca a fragmentos de bosque perennifolio de la vertiente occidental. Se desconoce el grado de amenza.

\section{Solanum inosinum 0choa}

\section{DD}

Publicación: Amer. Potato J. 58: 131133. 1981.

Colección tipo: $\mathrm{C}$. O choa 3608

Henbarios: LE.

Nombre común: Papa del gentil.

Registro departamental: CA.

Regiones Ecológicas: $\mathrm{PAR}, \mathrm{BMHM}$; 2600-3350 m.

SINAN PE: Sin registro.

Herbarios penuanos: MOL (8), USM (5).

Observaciones: Esta especie pertenece a Solanum Sección Petota. Se conoce de cuatro localidades, en los fragmentos de bosque montano ecotonales con jalca. O choa (1999) señala que es resistente a ataques de Phytophthora infestans. Se desconoce el grado de amenaza. 


\section{Solanum jaenense 0choa}

\section{DD}

Publicación: Agronomía (Lima) 27(4): 370-372. 1960.

Colección tipo: C. O choa 2328

Henbarios: ; MOL.

Nombre común: D esconocido.

Registro departamental: CA, PI.

Regiones Ecológicas: PAR, BMHM; $2700-2800 \mathrm{~m}$.

SINANPE: Sin registro.

Herbarios peruanos: MOL (isotipo citado+1), USM (1).

Observaciones: Esta especie pertenece a Solanum Sección Petota y se conoce solamente de dos localidades en el norte del país. Se desconoce el grado de amenaza.

162. Solanum jalcae Ochoa

\section{NE}

Publicación: Agronomía (Lima) 19: 167169, f. 1-2. 1954.

Colección tipo: C. Ochoa 1433

Herbarios: GH, LE, US; MOL.

Nombre común: Papa de zorro.

Registro departamental: AN, CA, LL, LI. Regiones Ecológicas: PAR; $3100-4300 \mathrm{~m}$. SINAN PE: Sin registro.

Herbarios peruanos: CPUN (2), HAO (12), HUT (6), MOL?, USM (6).

Observaciones: Hierba tuberífera que pertenece a Solanum Sección Petota. Se conoce de varias localidades paramunas, del norte y centro del pais. O choa (1999) indicó el poco éxito en el cruzamiento de esta especie con otras en la Sección, excepto con unas pocas como Solanum chomatophilum del Perú y Ecuador.

\section{Solanum laxissimum Bitter}

\section{NE}

Publicación: Bot. Jahrb. Syst. 54: 7-8. 1916. Colección tipo: A. Weberbauer 6640 Herbarios: $F, G H$; MOL.

Nombre común: Papa de monte, papa cholón. Registro departamental: $\mathrm{AY}, \mathrm{CU}, \mathrm{HU}$, JU, PA.

Regiones Ecológicas: BMHM; 1800$3100 \mathrm{~m}$.

SINANPE: SHMP, PNM

Herbarios peruanos: CUZ (1), HUT(1), MOL (18), USM (4).

Observaciones: Esta especie pertenece a Solanum Sección Petota. Se conoce de varias localidades en el centro del país. O choa (1999) logró éxitos en el cruzamiento de esta especie con otras en la Sección.

\section{Solanum lignicaule Vargas}

\section{DD}

Publicación: Revista Argent. Agron. 10: 3981943.

Colección tipo: C. Vargas C. 1539

Herbarios: F, G, GH, K, LL; CUZ.

Nombre común: Atokk papa.

Registro departamental: CU.

Regiones Ecológicas: MA; 2700-3400 m.

SINANPE: SHMP

Herbarios peruanos: CUZ (holotipo

citado), MOL (1).
Observaciones: Especie herbácea, diploide, perteneciente a Solanum Sección Petota, conocida de una subcuenca del Apurímac. O choa (1999) sugiere su potencial valor para mejoramiento genético en el control de áfidos. Se desconoce el grado de amenaza.

\section{Solanum limbaniense 0 choa}

\section{NE}

Publicación: Bol. Soc. Peruana Bot. 7(12): 14, 15-19. 1974.

Colección tipo: C. Ochoa 5165

Herbarios: CIP, LE, MO.

Nombre común: Puyuli.

Registro departamental: PU.

Regiones Ecológicas: $\mathrm{PSH}, \mathrm{BMHM}$; 3350- $4815 \mathrm{~m}$.

SINAN PE: Sin registro.

Herbarios penuanos: MOL (11), USM (9).

Observaciones: Esta especie diploide pertenece a Solanum Sección Petota. Compatible durante cruzamiento con varias especies en esta Sección (O choa, 1999). Se conoce de varias localidades en la Provincia de Sandia en Puno.

\section{Solanum longiusculus 0 choa}

\section{DD}

Publicación: Phytologia 63(5): 329. 1987.

Colección tipo: C. O choa 4125

Hembarios: US.

Nombre común: D esconocido.

Registro departamental: AP.

Regiones Ecológicas: MA, PSH; 2950$3400 \mathrm{~m}$.

SINANPE: Sin registro.

Hembarios peruanos: MOL (1), USM (1).

Observaciones: Esta especie diploide pertenece a Solanum Sección Petota. Solamente se conoce de una localidad, en la cuenca del río Vilcabamba, en el Departamento de Apurímac. Se desconoce el grado de amenaza.

\section{Solanum lopez-camarenae 0choa}

\section{DD}

Publicación: Anales Ci. Univ. Nac. Agrar. 12(1-2):12-16. 1979.

Colección tipo: C. Ochoa 3606

Hembarios: MO, US; MOL.

Nombre común: Papa del zorro.

Registro departamental: CA.

Regiones Ecológicas: BMHM; 2500$3000 \mathrm{~m}$.

SINANPE: Sin registro.

Herbarios penuanos: MOL (isotipo+3).

Observaciones: Esta especie diploide pertenece a Solanum Sección Petota. O choa (1999) señala que es resistenteal ataque deP hytophthora infestans. Se conoce de tres localidades en la Provincia de Cutervo. Se desconoce el grado de amenaza. 
168. Solanum marinasense Vargas

\section{DD}

Publicación: Papas Sudper. 2: 53. 1956.

Colección tipo: C. Vargas C. 4073

Hembarios: LL; CUZ.

Nombre común: D esconocido.

Registro departamental: AP, CU.

Regiones Ecológicas: MA; 2000-3700

m.

SINANPE: Sin registro.

Herbarios penuanos: CUZ (holotipo+3).

Observaciones: Esta especie pertenece a Solanum Sección Petota, se conoce de varias localidades, en el centro-sur del país, en las cuencas del Apurímac y Urubamba. Se desconoce el grado de amenaza.

\section{Solanum medians Bitter}

\section{DD}

Publicación: Repert. Spec. Nov. Regni Veg. 11: 3661912.

Colección tipo: A. Weberbauer 5683; Seler

260260

Hembarios: F, GH, US.

Nombre común: Añaz papa.

Registro departamental: AR, HV, LI, MO

Regiones Ecológicas: D ST, MDE, MA; 350-3700 m.

SINAN PE: RNL

Herbarios penuanos: MOL (6), USM (4).

Observaciones: Este taxón incluye, en condiciones naturales, individuos diploides y triploides. Pertenece a Solanum Sección Petota y se conoce de poblaciones naturalmente fragmentadas principalmente en la costa y piedemonte occidental. Esta especie exhibe dos diferentes épocas de floración dependiendo si viven en la costa o en las vertientes andinas. Se desconoce el grado de amenaza.

\section{Solanum mochiquense 0 choa}

\section{DD}

Publicación: Agronomía (Lima) 26(2): 111- 112. 1959.

Colección tipo: C. O choa 1822

Herbarios: MO.

Nombre común: Papita de lomas, papita silvestre, papita de zorro.

Registro departamental: LL, LI, PI.

Regiones Ecológicas: D ST, MDE; 300$1950 \mathrm{~m}$.

SINAN PE: Sin registro.

Herbarios penuanos: HUT (isotipo+5)?, MOL (isotipo+1)?, USM (isotipo+2)?

Observaciones: Esta especie diploide pertenece a Solanum Sección Petota y se conoce de más de diez localidades. O choa (1999) indicó su potencial para mejoramiento genético, por presentar resistencia a altas temperaturas y a varios virus. Se desconoce el grado de amenaza.
171. Solanum multïntemuptum Bittervar. multiintemuptum

NE

Publicación:

Colección tipo: J. McLean s.n.

Hemarios: $\mathrm{K}$.

Nombre común: Papa cimarrona (planta).

Registro departamental: AN, HV, LI.

Regiones Ecológicas: MA, PSH; 2750$3950 \mathrm{~m}$

SINAN PE: Sin registro.

Herbarios penuanos: CPUN (1), MOL (3), USM (4).

Observaciones: Esta especie pertenece a Solanum Sección Petota. Se conoce de varias localidades, en las partes altas del centro del país. Aparentemente forma híbridos con otras especies en la Sección.

\section{Solanum multiinterruptum Bitter var. machaytambinum 0choa}

\section{DD}

Publicación: Agronomía (Lima) 27(3): 244. 1960.

Colección tipo: C. Ochoa 2164

Herbarios: US; MOL.

Nombre común: Desconocido.

Registro departamental: LL.

Regiones Ecológicas: MA; $3000 \mathrm{~m}$.

SINANPE: Sin registro.

Herbarios penuanos: MOL (isotipo).

Observaciones: Este taxón pertenece a Solanum Sección Petota y se conoce solamente de una localidad en La Libertad. Se desconoce el grado de amenaza.

173. Solanum muphyi I.M. Johnst.

$$
\text { CR, Blab(iii) }
$$

Publicación: Contr. Gray Herb. 95: 34. 1931. Colección tipo: R.C. Murphy 3219

Herbarios: GH.

Nombre común: D esconocido.

Registro departamental: IC.

Regiones Ecológicas: D ST; altitud desconocida.

SINANPE: RNP

Herbarios peruanos: Ninguno.

Observaciones: Esta hierba, suculenta y probablemente efímera, se conoce sólo de una localidad, ubicada en islas guaneras, frente a las costas de Ica, con vegetación de lomas. No fue incluida por Brako \& Zarucchi (1993) entre las especies endémicas de la familia, pero aquí se confirma su estatus de endemismo. Al parecer, no ha vuelto a ser recolectada desde 1919.

\section{Solanum naucinum S. Knapp}

\section{DD}

Publicación: Ann. Missouri Bot. Gard. 92: 251-253, f. 2B . 2005.

Colección tipo: D.N. Smith \& J. Canne 5793

Herbarios: MO; USM.

Nombre común: D esconocido.

Registro departamental: PA

Regiones Ecológicas: BMHM; $2400 \mathrm{~m}$. SINANPE: PNYC

Hemarios peruanos: USM (holotipo). 
Observaciones: Esta especie arbustiva se conoce solamente de la localidad original, en la cuenca del Chontabamba. Al parecer, es localmente rara. Se desconoce el grado de amenaza.

\section{Solanum nemorosum Ochoa}

\section{DD}

Publicación: Amer. Potato J. 60(6): 389— 392. 1983.

Colección tipo: C. Ochoa \& A. Salas 14809

Hembarios: US; CPUN, MOL.

Nombre común: Desconocido.

Registro departamental: CA.

Regiones Ecológicas: BMHM; $2800 \mathrm{~m}$.

SINAN PE: Sin registro.

Herbarios peruanos: MOL (isotipo)

Observaciones: Esta especie hexaploide pertenece a Solanum Sección Petota y está restringida a una localidad, en la cuenca del Tabaconas, en bosques húmedos. Se desconoce el grado de amenaza.

\section{Solanum neovargasii Ochoa}

\section{DD}

Publicación: Los Solanum Tuberiferos Silvestres del Perú 53- 57, f. 16. 1963.

Colección tipo: C. O choa 2343

Herbarios: ; MOL, USM.

Nombre común: D esconocido.

Registro departamental: JU.

Regiones Ecológicas: BMHM; $2800 \mathrm{~m}$.

SINAN PE: Sin registro.

Herbarios peruanos: MOL (isotipo), USM

(isotipo citado).

Observaciones: Esta especie diploide pertenece a Solanum Sección Petota. Se conoce solamente de una localidad en la cuenca del Tulumayo. Se desconoce el grado de amenaza.

\section{Solanum nubicola 0 choa}

\section{DD}

Publicación: Anales Ci. Univ. Nac. Agrar. 8(3-4): 143-146. 1970.

Colección tipo: $\mathrm{C}$. O choa 2648

Herbarios: US.

Nombre común: Papa de zorro.

Registro departamental: HU, LL.

Regiones Ecológicas: PSH, PAR; 3300$3600 \mathrm{~m}$.

SINANPE: Sin registro.

Herbarios peruanos: Ninguno.

Observaciones: Esta especie tetraploide pertenece a Solanum Sección Petota. Se conoce de unas seis localidades, en el nortey centro del país, en la cuenca del Marañón. Se desconoce el grado de amenaza.

\section{Solanum oblongum Ruiz \& Pav.}

\section{VU, Bla}

Publicación: Fl. Peruv. 2: 34, pl. 165, f. b. 1799.

Colección tipo: H. Ruiz \& J. Pavón s.n.

Herbarios: MA.

Nombre común: Desconocido.

Registro departamental: $\mathrm{HU}, \mathrm{PA}, \mathrm{SM}$.

Regiones Ecológicas: BMHM; 1400-

$3000 \mathrm{~m}$.

SINAN PE: Sin registro.

Hembarios penuanos: USM (4).
Observaciones: Esta especie pertenece a Solanum Sección $\mathrm{G}$ eminata. Se conoce del centro del país, de más de cinco localidades, principalmente alrededor del Parque Nacional Yanachaga-Chemillén. Knapp (2002) indica que esta especie es localmente frecuente.

\section{Solanum orophilum Correll}

DD

Publicación: Wrightia 2: 192. 1961. Colección tipo: D.S. Correll \& E.E. Smith 971

Herbanios: K, LL-TEX, S, US.

Nombre común: Papa del zorro (planta), coilochumpa (fruto).

Registro departamental: AN, HU, LL.

Regiones Ecológicas: MA, PSH; 2700$4000 \mathrm{~m}$.

SINAN PE: Sin registro.

Hembarios penuanos: MOL (3), USM (2).

Observaciones: Esta especie pertenece a Solanum Sección Petota. Se conoce de varias localidades, principalmente en el centro del país. Probablemente se halle representada en el Parque Nacional Huascarán. Se desconoce el grado de amenaza.

\section{Solanum ortegae 0 choa}

\section{NE}

Publicación: Phytologia 85(4): 271. 1998.

Colección tipo: C. O choa 4094

Henbarios: ; USM!.

Nombre común: Akko papa.

Registro departamental: AP.

Regiones Ecológicas: MA; $2600 \mathrm{~m}$.

SINANPE: Sin registro.

Hemarios peruanos: USM (isotipo).

Observaciones: Esta especie diploide pertenece a Solanum Sección Petota. O choa (1999) no la incluyó en su monografía de las papas del Perú. Esta especie fue recolectada de la cuenca del Matará.

\section{Solanum pampasense Hawkes}

\section{DD}

Publicación: Bull. Imp. Bur. Pl. Breed. \& Genet., Cambridge 50: 125, f. 40. 1944. Colección tipo: E.P.K. Balls \& J.G. Hawkes 7007

Herbarios: CPC, $\mathrm{K}$.

Nombre común: D esconocido.

Registro departamental: AP, AY. Regiones Ecológicas: MA; 2300- 2700 m.

SINANPE: Sin registro.

Herbarios peruanos: Ninguno.

Observaciones: Especie herbácea que pertenece a Solanum Sección Petota. La mayoría de los registros son de plantas en cultivo, provenientes de la población de Apurímac. El ejemplar tipo fue recolectado de la cuenca del Pampas. Se desconoce el grado de amenaza. 


\section{Solanum paucissectum 0 choa}

\section{DD}

Publicación: Agronomía (Lima) 24(4): 365. 1960.

Colección tipo: C. O choa 2321

Herbarios: US.

Nombre común: D esconocido.

Registro departamental: CA, PI.

Regiones Ecológicas: MA, PAR; 2600$3660 \mathrm{~m}$.

SINANPE: Sin registro.

Hemarios penuanos: MOL (1)?

Observaciones: Esta especie diploide pertenece a Solanum Sección Petota. Se conoce de dos localidades en el norte del país; el ejemplar tipo proviene de la cuenca del Huancabamba. Se desconoce el grado de amenaza.

\section{Solanum peloquinianum 0 choa}

\section{NE}

Publicación: Amer. Potato J. 57: 33. 1980.

Colección tipo: C. O choa 13322

Herbarios: LE, MO, US; MOL.

Nombre común: Papa de pájaro.

Registro departamental: AN.

Regiones Ecológicas: MDE, MA; 1720-

$2300 \mathrm{~m}$.

SINANPE: Sin registro.

Herbarios penuanos: MOL (isotipo).

Observaciones: Especie herbácea diploide que pertenece a Solanum Sección Petota y conocida de cuatro localidades, aisladas entre ellas, en el norte del país. Hibridiza con otras especies en diferentes series (O choa, 1999).

\section{Solanum perlongistylum G.J. Anderson et al.}

$$
\text { VU, Bla }
$$

Publicación: Novon 16(2): 162-164, f. 1. 2006.

Colección tipo: C.T. Martine 953

Herbarios: CONN, MO, NY, US; MOL.

Nombre común: Nokai, pepino de monte.

Registro departamental: AY, HV.

Regiones Ecológicas: MA; 2100-3200 m.

SINAN PE: Sin registro.

Hembarios penuanos: MOL (isotipo citado).

Obsenvaciones: Arbusto escandente, al parecer, restringido a la cuenca del Apurímac. Los frutos de esta especie son apreciados como alimento en parte de la cuenca. Tiene potencial genético por su afinidad con el «pepino» (Anderson et al., 2006). Habita ambientes intervenidos como bordes de chacras y laderas con matorrales. Por su rango aparentemente restringido, se concuerda con la categoría de Vulnerable aplicada por Anderson et al. (2006).

\section{Solanum pillahuatense Vargas}

\section{DD}

Publicación: Las Papas Sudperuanas, Parte II, 53- 54. 1956.

Colección tipo: C. Vargas C. 4924

Herbarios: TEX-LL; CUZ

Nombre común: D esconocido.

Registro departamental: CU.

Regiones Ecológicas: BMHM; 2750$3650 \mathrm{~m}$.

SINAN PE: Ninguno.

Herbarios peruanos: CUZ (holotipo

citado), MOL (3).
Observaciones: Esta especie pertenece a Solanum Sección Petota y se conoce de dos localidades, al suroeste de los límites del Parque Nacional Manu. Se desconoce el grado de amenaza.

\section{Solanum piurae Bitter}

\section{DD}

Publicación: Bot. Jahrb. Syst. 54(Beibl. 119): 5-6. 1916.

Colección tipo: A. Weberbauer 6370

Herbarios: $B(d), F$.

Nombre común: Papa de zorro.

Registro departamental: CA, LL, PI. Regiones Ecológicas: MA; 2300-3200 m. SINAN PE: Sin registro.

Herbarios penuanos: MOL (2), USM (4).

Observaciones: Esta especie diploide pertenece a Solanum Sección Petota y se conoce solamente del norte del país. El ejemplar tipo fue recolectado dela cuenca del Quiroz. Se desconoce el grado de amenaza.

\section{Solanum raphanifolium Cárdenas \& H awkes}

\section{NE}

Publicación: J. Linn. Soc., Bot. 53: 94, f. 1. 1946.

Colección tipo: M. Cárdenas \& $H$. Gandarillas 3500

Herbarios: $\mathrm{K}$.

Nombre común: D esconocido.

Registro departamental: AP, CU, PU.

Regiones Ecológicas: MA, PSH, BMHM; 2000- $4200 \mathrm{~m}$.

SINAN PE: SHMP

Henbarios peruanos: USM (2).

Observaciones: Esta especie herbácea pertenece a Solanum Sección Petota. Se conoce del sur del país. Al parecer podría tener un origen híbrido (O choa, 1999), aunque Spooner et al. (1991) hallaron que esta propuesta no tenía sustento con análisis de AD N.

\section{Solanum raquialatum 0 choa}

\section{NE}

Publicación: Agronomía (Lima) 19: 172174, f. 6- 7. 1954.

Colección tipo: H.E. Stork 11394

Hemanios: G, GH, NA, UC.

Nombre común: Papa de wisco.

Registro departamental: PI.

Regiones Ecológicas: MDE, MA; 1200— $2800 \mathrm{~m}$.

SINAN PE: Sin registro.

Herbarios peruanos: MOL (2).

Observaciones: Esta especie diploide pertenece a Solanum Sección Petota. Se conoce de unas seis localidades, todas ubicadas en la vertiente occidental del Departamento de Piura. Ochoa (1999) señala la facilidad de cruzamiento con otras especies afines a esta y otras más lejanas. 


\section{Solanum rhomboideilanceolatum 0choa}

\section{DD}

Publicación: Revista Argent. Agron. 19: 234-237, f. 3-4. 1952.

Colección tipo: C. O choa 1394

Herbarios: K, US; USM!.

Nombre común: D esconocido.

Registro departamental: AY, JU.

Regiones Ecológicas: BMHM; 2200$4280 \mathrm{~m}$.

SINAN PE: PNH

Herbarios peruanos: USM (isotipo+6).

Observaciones: Esta especie diploide pertenece a Solanum Sección Petota. Se conoce de la cuenca del Mantaro. Se desconoce el grado de amenaza.

\section{Solanum ruizii S. Knapp}

\section{EN, Blab(iii)}

Publicación: Bull. Brit. Mus. (Nat. Hist.), Bot. 19: 91-94, f. 17-18. 1989.

Colección tipo: H. Ruiz \& J. Pavón s.n.

Herbarios: MA.

Nombre común: Desconocido.

Registro departamental: HU, HV.

Regiones Ecológicas: PSH, BPM; 3000$4200 \mathrm{~m}$.

SINAN PE: Sin registro.

Herbarios peruanos: Ninguno.

Observaciones: Planta arbórea o arbustiva, conocida del centro del país, de la cuenca alta de los ríos Pozuzo y Mantaro. Aparentemente localmente frecuente, pero no hay recolectas conocidas desde 1937. Knapp (1989) indica que las localidades de esta especie probablemente estén afectadas por la deforestación. O tro aspecto a considerar es que el área de presencia de esta especie ha sido poco herborizada.

\section{Solanum salasianum Ochoa}

DD

Publicación: Amer. Potato J. 66(4): 235238. 1989.

Colección tipo: C. Ochoa 4629

Herbarios:

Nombre común: Jacha papa.

Registro departamental: HU.

Regiones Ecológicas: BMHM; 2600$3000 \mathrm{~m}$.

SINAN PE: Sin registro.

Hemarios penuanos: MOL (2), USM (1).

Observaciones: Esta especie diploide pertenece a Solanum Sección Petota. Se conoce solamente de unas pocas localidades, en la cuenca del Huallaga. Se desconoce el grado de amenaza.

\section{Solanum sandemanii Hawkes}

\section{DD}

Publicación: Ann. \& Mag. Nat. Hist. ser. 12, 7: 709, f. 12-13. 1954.

Colección tipo: F.W. Pennell 13196

Herbarios: F, GH, K, NY, PH, S.

Nombre común: Tomatillo.

Registro departamental: AR.

Regiones Ecológicas: MA; 2500-3800 m.

SINAN PE: Sin registro.

Herbarios penuanos: CUZ (4).
Observaciones: Esta especie diploide que pertenece a Solanum Sección Petota, se conoce solamente del sur del país. Se presenta en un área menor a los 10,000 km². Según O choa (1999) se conoce solamente de Arequipa. Se desconoce el grado de amenaza.

\section{Solanum santolallae Vargas}

\section{DD}

Publicación: Revista Argent. Agron. 10(4): 397. 1943.

Colección tipo: C. Vargas C. 3504

Hembarios: $\underline{\text { CUZ. }}$.

Nombre común: Papa de monte.

Registro departamental: CU.

Regiones Ecológicas: BMHM; 1800$3580 \mathrm{~m}$.

SINANPE: PNM, SHMP

Herbarios peruanos: CUZ (lectotipo), MOL (1).

Observaciones: Esta especie diploide pertenece a Solanum Sección Petota. Se conoce solamente de unas siete localidades, en las partes orientales deCusco. Vargas (1949) mencionaqueestaespecieestípicade bosques de la «Ceja de selva». Se desconoce el grado de amenaza.

\section{Solanum sarasarae 0 choa}

\section{EN, B 1ab(iii)}

Publicación: Phytologia 64: 245. 1988.

Colección tipo: C. Ochoa 4197

Herbarios: US.

Nombre común: D esconocido.

Registro departamental: AY.

Regiones Ecológicas: MA, PSH; 3000$4000 \mathrm{~m}$.

SINANPE: Sin registro.

Herbarios peruanos: CPUN (2), USM (2).

Observaciones: Esta especie herbácea diploide pertenecea Solanum Sección Petota. Se conoce solamente de tres localidades en el suroeste de Ayacucho, cuenca alta del O coña, asociada a fragmentos de bosque altoandino.

\section{Solanum sawyeri Ochoa}

\section{NE}

Publicación: Amer. Potato J. 58(12): 650. 1981.

Colección tipo: C. O choa 2205

Henbarios: MOL, USM.

Nombre común: D esconocido.

Registro departamental: CU.

Regiones Ecológicas: BMHM; 2300$2800 \mathrm{~m}$.

SINANPE: Sin registro.

Herbarios peruanos: MOL (isotipo), USM (isotipo).

Observaciones: Esta especie herbácea se conoce de una localidad, muy cerca al Santuario Histórico Machu Picchu. Ochoa (1999) indicó la afinidad con Solanum sparsipilum, especie del Perú y Bolivia. 
196. Solanum saxatilis Ochoa

\section{NE}

Publicación: Phytologia 73(5): 378-380

1992.

Colección tipo: C. O choa \& A. Salas 15082

Herbarios: CIP, MO; MOL.

Nombre común: D esconocido.

Registro departamental: PU.

Regiones Ecológicas: MA, PSH; 3550$3650 \mathrm{~m}$.

SINAN PE: Sin registro.

Herbarios peruanos: MOL (isotipo+1).

Observaciones: Esta especie pertenece a Solanum Sección Petota y se conoce de dos localiades en la Provincia de Sandia en Puno.

\section{Solanum scabrifolium 0 choa}

\section{DD}

Publicación: Darwiniana 17: 427-429. 1972.

Colección tipo: C. O choa 2633

Herbarios:

Nombre común: D esconocido.

Registro departamental: HU.

Regiones Ecológicas: MA; 2800-3300 m.

SINANPE: Sin registro.

Herbarios penuanos: MOL (1), USM (1)

Observaciones: Esta especie diploide pertenece a Solanum Sección Petota. Se conoce de tres localidades en Huánuco. Se desconoce el grado de amenaza.

\section{Solanum simplicissimum 0 choa}

\section{DD}

Publicación: Revista Acad. Colomb. Ci. Exact. 17(65): 321-323. 1989.

Colección tipo: C. O choa 4500

Herbarios: MOL.

Nombre común: Ñame.

Registro departamental: LI.

Regiones Ecológicas: MDE, MA; 1600 $2200 \mathrm{~m}$.

SINAN PE: Sin registro.

Herbarios peruanos: MOL (isotipo+2), USM (1).

Observaciones: Esta especie diploide pertenece a Solanum Sección Petota y se conoce delas vertientes occidentales de Lima. Se desconoce el grado de amenaza.

\section{Solanum sogarandinum 0 choa}

\section{NE}

Publicación: Agronomía (Lima) 19: 168171, f. 3-5. 1954.

Colección tipo: C. Ochoa 1440

Herbarios: CIP, US.

Nombre común: Desconocido.

Registro departamental: AN, CA, HU, LL.

Regiones Ecológicas: PSH, PAR; 3550$4400 \mathrm{~m}$.

SINANPE: PNH

Herbarios peruanos: USM (2).

Observaciones: Este taxón incluye poblaciones diploides, tetraploides y hexaploides. O choa (1999) reporta éxito en los cruzamientos con otras especies dela Sección incluyendo con Solanum tuberosum subsp. andigenum.
200. Solanum solum J.F. Macbr.

EN, Blab(iii)

Publicación: Field Mus. Nat. Hist., Bot. Ser. 13(5B/1): 220. 1962.

Colección tipo: J.F. Macbride 5764

Hembarios: $F$.

Nombre común: D esconocido.

Registro departamental: JU, PA.

Regiones Ecológicas: BMHP; $1000-$ $1500 \mathrm{~m}$.

SINAN PE: Sin registro.

Herbarios peruanos: Ninguno.

Observaciones: Esta especie arbustiva se conoce de dos localidades en el centro del país; al parecer, no ha vuelto a ser recolectada desde 1962. La localidad original, en el valle de Chanchamayo, ha sido mayormente modificada por la colonización incesante y expansión agnícola.

\section{Solanum sumacaspi S. Knapp}

\section{DD}

Publicación: Ann. Missouri Bot. Gard. 92: 248-251, f. 1, 2A. 2005.

Colección tipo: M. Ackermann \& D. Kollehn 289

Henbarios: BM, BSB, HUSA, M, NY; USM!. Nombre común: D esconocido.

Registro departamental: CU, PU.

Regiones Ecológicas: $\mathrm{MA}, \mathrm{BMHM}$; 2200- $3500 \mathrm{~m}$

SINANPE: SHMP

Herbarios penuanos: USM (tipo citado).

Observaciones: Esta especie recientemente segregada de Solanum daphnophyllum, se conoce de varias localidades en el sur del país. Se desconoce el grado de amenaza.

\section{Solanum tapojense 0 choa}

\section{NE}

Publicación: Phytologia 46(4): 223. 1980. Colección tipo: C. Ochoa 2789

Herbarios: CUZ, MOL, USM!.

Nombre común: Desconocido.

Registro departamental: PU.

Regiones Ecológicas: PSH; $3830-3850 \mathrm{~m}$. SINANPE: Sin registro.

Herbarios peruanos: CUZ (holotipo citado), MO L (isotipo citado). USM (isotipo citado).

Observaciones: Esta especie diploide pertenece a Solanum Sección Petota y se conoce de una localidad muy cerca al límite con Bolivia, en la cuenca del Titicaca.

\section{Solanum tarapatanum 0 choa}

\section{DD}

Publicación: Anales Ci. Univ. Agric. Lima 15: 1. 1977.

Colección tipo: C. O choa 2064

Herbarios: ; USM!.

Nombre común: Llutt'u papa.

Registro departamental: CU.

Regiones Ecológicas: MA; 2600-2900 m.

SINAN PE: Sin registro.

Herbarios peruanos: CUZ (holotipo), USM (isotipo). 
Observaciones: Esta especie diploide pertenece a Solanum Sección Petota y se conoce de una localidad en la cuenca del Urubamba. Se desconoce el grado de amenaza.

\section{Solanum taulisense 0 choa}

DD

Publicación: Lorentzia 4: 13. 1981.

Colección tipo: C. O choa 2654

Herbarios:

Nombre común: D esconocido.

Registro departamental: LL.

Regiones Ecológicas: PAR; 3700-3900 m.

SINANPE: Sin registro.

Hemarios peruanos: HUT?, CUZ?, USM?.

Observaciones: Esta especie herbácea de la jalca, se conoce solamente de una localidad en el norte del país, en la cuenca del Marañón. Se desconoce el grado de amenaza.

\section{Solanum tovanii S. Knapp}

$$
\text { EN, Bla }
$$

Publicación: Novon 2(4): 348-349, f. 5, 7. 1992.

Colección tipo: O. Tovar 1932

Hemarios: IBE; USM.

Nombre común: D esconocido.

Registro departamental: HV, JU.

Regiones Ecológicas: $\mathrm{MA}, \mathrm{BMHM}$; $2700-3300 \mathrm{~m}$.

SINANPE: Sin registro.

Hembarios penuanos: USM (tipo citado).

Observaciones: Esta especie arbustiva pertenece a Solanum Sección $\mathrm{G}$ eminata. Se conoce de cuatro localidades en el centro del país, en áreas ecotonales entre bosque húmedo y ambientes cismontanos. No ha vuelto a ser recolectada desde 1954 . Amenazas potenciales a sus poblaciones probablemente estén asociadas a modificación del ambiente por incendios y/ o deforestación.

\section{Solanum trinitense 0 choa}

\section{DD}

Publicación: Anales Ci. Univ. Agr. Lima 11(3): 245-247. 1964.

Colección tipo: C. O choa 2486

Herbarios: LE.

Nombre común: D esconocido.

Registro departamental: CA.

Regiones Ecológicas: MA; 2700-3400 m.

SINANPE: Sin registro.

Herbarios peruanos: MOL (3), USM (2).

Observaciones: Esta especie pertenece a Solanum Sección Petota, se conoce de cuatro localidades, en la vertiente occidental de Cajamarca. Brako \& Zarucchi (1993) señalaron a Apurímac en el rango de distribución de esta especie, pero O choa (1999) la limita a Cajamarca. Se desconoce el grado de amenaza.

\section{Solanum unubambae Juz.}

\section{DD}

Publicación: Bull. Acad. Sci. U.R.S.S., ser. Biol. 2: 312-313. 1937.

Colección tipo: S.V. Juzepczuk 10973

Herbarios: LE.

Nombre común: D esconocido.

Registro departamental: AP, CU.

Regiones Ecológicas: BMHM; 2500-

$3400 \mathrm{~m}$.

SINAN PE: SHMP, PNM
Herbarios penuanos: MOL (1), USM (16).

Observaciones: Especie diploide que pertenece a Solanum Sección Petota, se conoce de varias localidades, en la vertiente oriental de Cusco. Se desconoce el grado de amenaza.

\section{Solanum velardei 0 choa}

\section{DD}

Publicación: Anales Ci. Univ. Nac. Agrar. 1(3): 216-220. 1963.

Colección tipo: C. O choa 2412

Herbarios:

Nombre común: Atokk papa.

Registro departamental: AP.

Regiones Ecológicas: MA; 2400-3400

m.

SINAN PE: Sin registro.

Hembarios peruanos: Ninguno.

Observaciones: Esta especie diploide pertenece a la Sección Petota y se conoce de varias localiades, en la cuenca del Apurímac. Se desconoce el grado de amenaza.

\section{Solanum wittmackii Bitter}

\section{DD}

Publicación: Repert. Spec. Nov. Regni Veg. 12: 54. 1913.

Colección tipo: A. Mathews 847 p.p.

Hemarios: BM, CGE, E, GH, GL, OXF.

Nombre común: Papa cimarrón, papa del gentil, papita de San Juan.

Registro departamental: LI.

Regiones Ecológicas: D ST, MA; 300$3400 \mathrm{~m}$.

SINAN PE: Sin registro.

Herbarios penuanos: MOL (3), USM (8).

Observaciones: Esta especie pertenece a Solanum Sección Petota. Se conoce de varias localidades en Lima. Habita en dos rangos altitudinales bien definidos, uno que no supera los $600 \mathrm{~m}$ y el otro de los 2000 a su rango altitudinal superior. O choa (1999) considera que probablemente habita las islas frente a Lima. Se desconoce el grado de amenaza.

\section{Solanum $x$ arahuayum 0 choa}

\section{NE}

Publicación: Phytologia 77(2): 96- 98, pro sp. 1994.

Colección tipo: G. Vilcapoma 208

Herbarios: US; CPUN, MOL, USM!.

Nombre común: Papa de gentil.

Registro departamental: LI.

Regiones Ecológicas: MA; 2650-3200 m.

SINANPE: Sin registro.

Hembarios penuanos: USM (isotipo+1).

Observaciones: Este taxón es el resultado de la hibridación natural entre Solanum medians y S. wittmadkii. 


\section{Solanum $x$ blanco-galdosii 0 choa}

\section{NE}

Publicación: Anales Ci. Univ. Nac. Agrar. 11: N. (3-4) p. 157-160, pro sp. 1973.

Colección tipo: C. O choa 2714

Herbarios: US; USM!.

Nombre común: Papa del gentil.

Registro departamental: AN, CA.

Regiones Ecológicas: MA, PAR; 2050$3100 \mathrm{~m}$.

SINAN PE: Sin registro.

Herbarios peruanos: USM (isotipo+1).

Observaciones: Ochoa (1999) indica que es un híbrido entre Solanum chomatophilum y S. peloquinianum. Se conoce de ambientes paramunos en cuatro localiades principalmente en Cajamarca.

\section{Solanum $x$ neoweberbaueri Wittmack}

\section{NE}

Publicación: Bot. Jahrb. Syst. 50(Suppl.): 540, f. 1-2, pro sp. 1914.

Colección tipo: A. Weberbauer 5689

Herbarios: F, GH, GOET, S.

Nombre común: D esconocido.

Registro departamental: LI.

Regiones Ecológicas: D ST; 200- 700 m. SINANPE: Sin registro.

Hemarios peruanos: MOL (3), USM (3).

Observaciones: Ochoa (1999) indica que es un híbrido entre Solanum medians y S. chancayense. Se conoce solamente de ambientes de lomas. Elárea de presencia no supera los $1000 \mathrm{~km}^{2}$ y se presume que en la localidad original ha desaparecido.

\section{Solanum xanthophaeum Bitter}

\section{DD}

Publicación: Repert. Spec. Nov. Regni Veg. 16: 401.1920.

Colección tipo: A. Weberbauer 3690

Henbarios: G; MOL!.

Nombre común: Ayac mullaca.

Registro departamental: CA, HU, PA, SM.

Regiones Ecológicas: $\mathrm{BMHM}, \mathrm{BMHP}$; $500-2000 \mathrm{~m}$.

SINANPE: PNYC

Henbarios penuanos: MOL (isotipo), USM (2).

Observaciones: Esta especie herbácea pertenece a la Sección $\mathrm{G}$ eminata. La mayoría, de las localidades conocidas, provienen del centro oriente del país, de las cuencas del Huallaga y del Huancabamba. Se desconoce el grado de amenaza.

\section{Solanum yanamonense S. Knapp}

\section{CR, Bla}

Publicación: Brittonia 38(3): 298-299, f. 15, 17. 1986.

Colección tipo: S. Knapp 6613

Herbarios: BH, NY, US; USM.

Nombre común: D esconocido.

Registro departamental: LO.

Regiones Ecológicas: BHA; 100-120 m. SINAN PE: Sin registro.

Herbarios penuanos: USM (isotipo+2).

Observaciones: Esta especie herbácea pertenece a la Sección $\mathrm{G}$ eminata y se conoce de los bosques de los alrededores de Iquitos, al parecer, sólo en un área de reserva privada (Explorama). No fue incluida por Vásquez (1997) en la flora de esa área. Los bosques de los alrededores de la ciudad de Iquitos tienen fuerte impacto en sus ambientes principalmente por la extracción forestal. 
Mapa del Perú indicando las abreviaturas de los departamentos

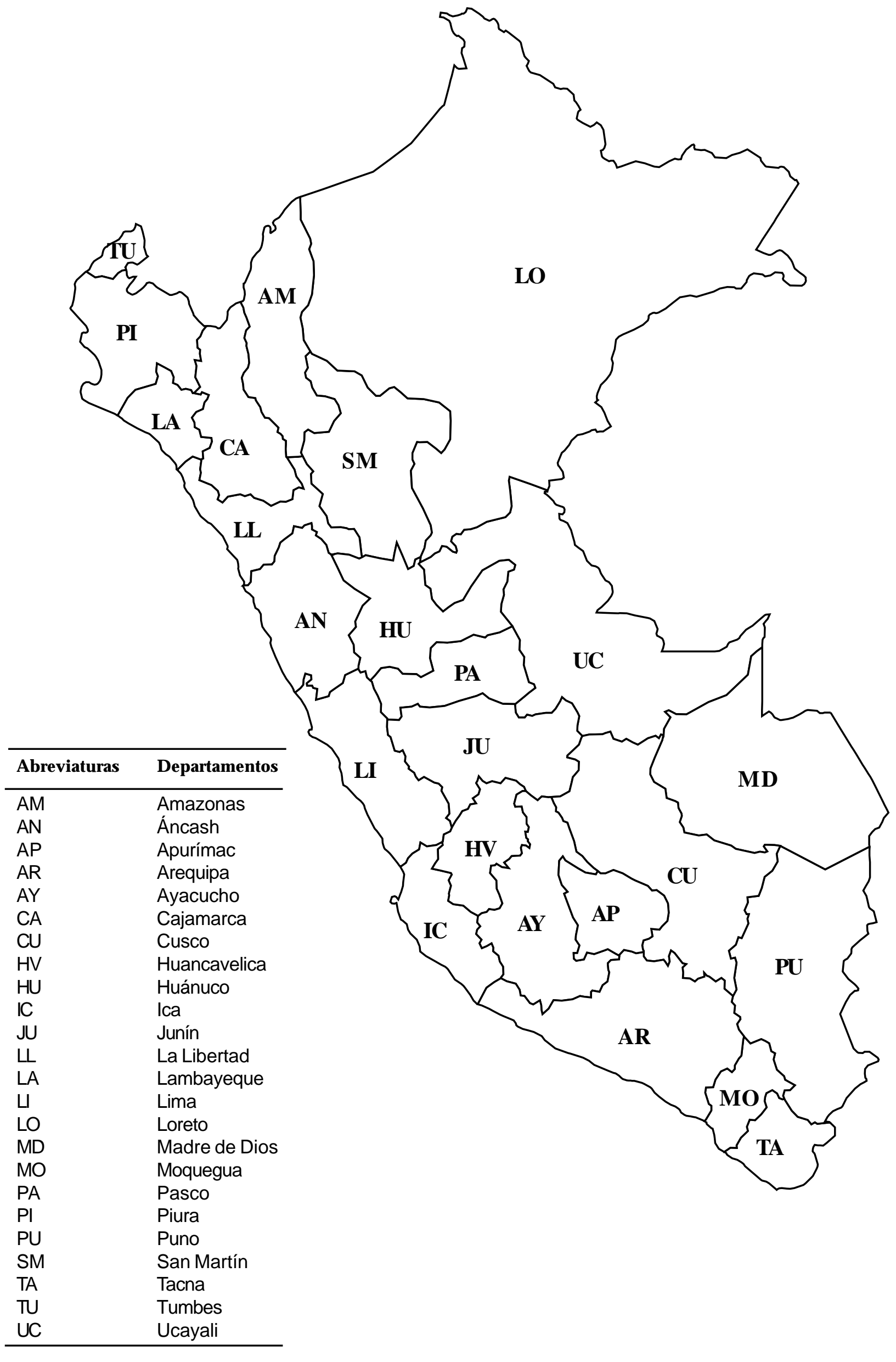

